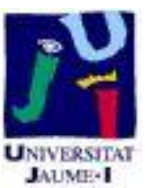

Título artículo / Títol article: Calcium carbonate decomposition in white-body tiles during firing in the presence of carbon dioxide

Escardino Benlloch, Agustín ; Gómez Tena, María

Autores / Autors

Pilar; Feliu Mingarro, Carlos ; García Ten, Francisco

Javier; Saburit Llaudis, Alejandro

Revista:

Ceramics International, 2013, vol. 39, no 6

Versión / Versió:

Cita bibliográfica / Cita bibliogràfica (ISO 690):
Preprint del autor

ESCARDINO, A., et al. Calcium carbonate decomposition in white-body tiles during firing in the presence of carbon dioxide. Ceramics International, 2013, vol. 39, no 6, p. 6379-6390 


\title{
Calcium car bonate decomposition in white-body tiles during firing in the presence of carbon dioxide
}

\author{
A. ESCARDINO*, J. GARCÍA-TEN, A. SABURIT, C. FELIU, M. P. GÓMEZ-TENA \\ Instituto de Tecnología Cerámica. Asociación de Investigación de las Industrias Cerámicas. \\ Universitat Jaume I. Castellón. Spain.
}

\begin{abstract}
This study examines the thermal decomposition process of the calcium carbonate (calcite powder) contained in test pieces of porous ceramics, of the same composition as that used in manufacturing ceramic wall tile bodies, in the presence of carbon dioxide, in the temperature range $1123-1223 \mathrm{~K}$. The experiments were carried out in a tubular reactor, under isothermal conditions, in a gas stream comprising different concentrations of air and carbon dioxide.
\end{abstract}

Assuming that the relationship between the molar concentrations of $\mathrm{CO}_{2}$ on both sides of the gas-solid interface in the test pieces was conditioned by an equilibrium law of the form $c_{Q S}^{S}=$ $b \cdot c_{Q S}^{G}$, the equation proposed in a previous paper was modified to correlate the results obtained when the experiments were conducted in the presence of carbon dioxide. The modified equation fitted well to the experimental data obtained in the temperature and carbon dioxide concentration ranges studied.

The knowledge derived from this research has enabled the firing cycle used in the single-fire manufacture of this type of wall tile to be optimised.

\section{Introduction}

\subsection{Object of this research}

Calcite is the calcium compound that is usually added, as a source of $\mathrm{CaO}$, to the raw materials mixture used to form the tile body in the single-fire manufacturing process of whitebody wall tiles ${ }^{1}$. During firing, the calcite particles need to completely decompose before the

* Corresponding author. e-mail address. aescardino@itc.uji.es 
glaze melts and seals the tile surface in order to keep the $\mathrm{CO}_{2}$ released in the tile body by this reaction from being trapped as small bubbles in the molten glaze layer ${ }^{2}$.

In order to optimise the calcite decomposition stage in the industrial firing cycle used to manufacture this type of tile, it was deemed useful to have a mathematical expression that would relate the decomposition progress of the calcite contained in the tile body to the operating variables (time, temperature, tile shape and size, etc.).

The thermal decomposition process of very small calcite particles contained in ceramic compacts, analogous to those used in the manufacturing process to form white-firing earthenware tile bodies, has been studied in two previous papers ${ }^{3,4}$. The experiments were conducted in air atmosphere, at different temperatures, using disks of different initial porosity, thickness, and calcite content. The results were interpreted using an equation derived on applying the Shrinking Unreacted Core Kinetic Model.

These papers have been the first phase of a study which has yielded a kinetic model that takes into account the influence of the dimensional and structural characteristics of the test disk and of the chemical reaction of decomposition that is developed. This kinetic model satisfactorily describes the kinetics of the process when is conducted in air atmosphere.

In industrial practice, however, the thermal decomposition process of the calcite contained initially in the body of this type of tiles occurs in presence of a mixture of air and carbon dioxide that contains between $5-10 \% \mathrm{CO}_{2}$ by volume. This $\mathrm{CO}_{2}$ is formed by combustion of the natural gas that is feed directly in the industrial kiln to maintain the appropriate firing cycle.

It was considered convenient, therefore, to verify whether the proposed model could be used, introducing the appropriate modifications, when the process is conducted in presence of a mixture of air and carbon dioxide.

As a consequence, in this study, it was deemed of interest to conduct the experiments not covering only all the range of carbon dioxide concentrations in the gaseous phase, but 
working also in pure $\mathrm{CO}_{2}$ atmosphere, in order to try to propose a valid equation for a wide range of operating conditions. This might then allow related lines of research to be opened up.

\subsection{Background}

The equation used to correlate the experimental results in previous papers ${ }^{3,4}$ was of the following form (an explanation of the symbols is given in the Nomenclature):

$$
\frac{d X}{d t}=\left(\frac{1}{L \cdot C_{B}^{0}}\right) \cdot\left[\frac{K_{C}-b \cdot c_{Q}^{G}}{\frac{K_{C} \cdot S_{S}}{k \cdot S_{i} \cdot(1-X)^{1 / 3}}+\frac{L \cdot X}{4 \cdot D_{e}}}\right]
$$

In those papers, the value of the product $\left(b \cdot c_{Q}^{G}\right)$ was considered to be equal to zero because the experiments were conducted in an atmosphere free of $\mathrm{CO}_{2}\left(c_{Q}^{G}=0\right)$.

In the first paper ${ }^{3}$ equation (1) was derived by assuming that parameter $b$ was equal to one. This assumption can only be made when the carbon dioxide is completely insoluble or does not interact with the solid phase in contact with the $\mathrm{CO}_{2}$. However, it is obvious that the $\mathrm{CO}_{2}$ can interact with the calcium oxide resulting from calcite decomposition. This assumption is supported by the following facts:

a) A certain number of researchers ${ }^{5,6,7}$, on studying the thermal decomposition process of different varieties of limestone in the presence of carbon dioxide, have suggested the possible participation of an adsorption step of the $\mathrm{CO}_{2}$ on the $\mathrm{CaO}$ resulting from the decomposition of that compound.

b) The results obtained in a paper recently submitted for publication ${ }^{8}$, in which the thermal decomposition in $\mathrm{CO}_{2}$ atmosphere of small calcite particles, of the same nature as those introduced into the ceramic test pieces used in this research, was studied. Those results suggest that, at the gas-CaO interface, an equilibrium law of the form $c_{Q S}^{S}=b \cdot c_{Q S}^{G}$ appears to be obeyed.

c) The possible sorption of $\mathrm{CO}_{2}$ on the kaolinitic and illitic clays ${ }^{9}$ presents in the raw materials mixture used to form the test pieces used in the present study. 
This study, therefore, considers the possibility that $b \neq 1$ in equation (1), based on the assumption that the molar concentrations of $\mathrm{CO}_{2}$ in the gaseous phase, on both sides of the gas-solid interface, are different and that they are related by an equilibrium law of the form $c_{Q S}^{S}=b \cdot c_{Q S}^{G}$ (Appendix).

\section{Materials and experimental procedure}

\subsection{Materials}

The test disks (cylindrical pieces, $40 \mathrm{~mm}$ in diameter and $7 \mathrm{~mm}$ thick) used to conduct this study were formed by uniaxial pressing from a mixture of the same natural raw materials as those used in the previous papers ${ }^{3,4}$. The mixture consisted of illitic-kaolinitic clays $(60 \%)$, feldspathic sand (25\%), and calcite (15\%), all percentages by weight. Average calcite particle size was $0.007 \mathrm{~mm}$. Pressing powder moisture content was kept constant at $0.055 \mathrm{~kg}$ water $/ \mathrm{kg}$ dry solid. The initial porosity of the green test disks was $\varepsilon_{0}=0.229$ and calcium carbonate molar concentration in the disks, corresponding to disk calcite content, was $c_{B}{ }^{0}=2.925$ $\mathrm{kmol} / \mathrm{m}^{3}$ disk.

The side of each test disk was sealed with a glaze to prevent any lateral $\mathrm{CO}_{2}$ losses during thermal treatment, so that any gaseous product would only be released through the two faces of the disk.

\subsection{Experimental assembly and procedure}

The decomposition process was monitored by measuring sample weight loss during isothermal treatment in a laboratory tubular kiln (reactor). Air, $\mathrm{CO}_{2}$, or air and $\mathrm{CO}_{2}$ mixtures were fed into the kiln at a controlled temperature and flow rate. The assembly (Figure 1) consisted of a refractory steel sample-holder, set in the middle of the kiln firing chamber. The holder was suspended from a single-pan balance by an alumina rod so that sample mass could be continuously measured. The balance was connected to a computer with the appropriate software to record the pairs of mass-time values.

\section{Figure 1}


The test pieces were preheated for 30 minutes in an oven that ran at $373 \mathrm{~K}$. They were then placed in the reactor that was operating at the previously selected temperature and composition conditions of the gas phase.

The relationship between the real temperature of the test pieces and the temperature measured by the control thermometer in the kiln was determined before the experiments were initiated and the corresponding calibration line was plotted.

The details of the assembly and of the procedure used have been described in a previous paper (sections 2.3, 3.1, and 3.2) ${ }^{3}$.

All experiments were performed in the reactor under isothermal conditions. When the experiments were conducted in air atmosphere or in mixtures of $\mathrm{CO}_{2}$ and air, the operation was carried out at a sufficiently high gas flow rate through the reactor to ensure that $\mathrm{CO}_{2}$ transfer from the test disk interface to the gas phase would not influence the overall process rate $^{3}$. When the experiments were performed in $\mathrm{CO}_{2}$ atmosphere, the carbon dioxide concentration at the gas-disk interface, gas side $\left(C_{Q S}^{G}\right)$, was equal to its bulk concentration in the gas phase.

The DTA-TGA tests were performed in a Mettler TGA/SDTA 851e thermobalance at a heating rate of $10 \mathrm{~K} / \mathrm{min}$.

\subsection{Determination of calcium carbonate conversion during thermal treatment of the test pieces in the reactor}

The conversion degree $(X)$ of the $\mathrm{CaCO}_{3}$ content in the test piece versus residence time was calculated, in each experiment, from the expression:

$$
X=\frac{\Delta m_{B}}{\Delta m_{B f}}=\frac{m_{B 0}-m_{B}}{m_{B 0}-m_{B f}}=\frac{\left(m_{A B 0}-m_{A B}\right)-\left(m_{A 0}-m_{A}\right)}{\left(m_{A B 0}-m_{A B f}\right)-\left(m_{A 0}-m_{A f}\right)}
$$

where $\Delta m_{B}$ is the mass loss of calcite $(B)$ in the test pieces at a given residence time and $\Delta m_{B f}$ is the mass loss of $B$ in the sample at a sufficiently long time to achieve constant weight.

In order to obtain the mass loss curves for calcite decomposition in the test pieces $\left(\Delta m_{B}\right)$, it was necessary to perform two series of experiments in each case. In one series, the test pieces 
(referenced $P A B$ ) were formed from the mixture of clay, feldspathic sand, and calcite. In the other, the test pieces (referenced $P A$ ) were formed from the same mixture of clay and feldspathic sand (same quantities as in $P A B$ ) without the calcite.

The experiments carried out with the calcite-containing pieces yielded the curve $\Delta m_{A B}=f(t)$ of total mass loss with residence time. The experiments conducted on the test pieces without calcite, which contained the same quantity and same initial mass $\left(m_{A 0}\right)$ of the other components in the $P A B$ pieces, yielded the decomposition curve $\Delta m_{A}=f(t)$.

The value of $\Delta m_{B}$ at every residence time was obtained from the expression: $\Delta m_{B}=\Delta m_{A B}$ $\Delta m_{A}$ (for a more detailed description of the procedure used and of the symbols, please see the Nomenclature and the previous paper ${ }^{3}$ ).

\section{Experimental results and discussion}

\subsection{DTA-TGA experiments}

During heat treatment of the calcite-containing test pieces, $\mathrm{CaO}$ and $\mathrm{CO}_{2}$ evolved owing to calcium carbonate decomposition, while water vapour was released as a result of the dehydroxylation of the large quantity ( $60 \%$ by weight) of illitic-kaolinitic clays present in the test pieces.

In order to ascertain whether any type of interaction might occur between the water vapour, $\mathrm{CO}_{2}$, and the solid phase ( $\mathrm{CaO}$ and clays) present during the thermal treatment of the test pieces, DTA-TGA tests were conducted on samples of the test pieces milled to a particle size of about $1 \mathrm{~mm}$.

A number of tests were conducted in air atmosphere, while others were performed in $\mathrm{CO}_{2}$ atmosphere. In both cases the tests were carried out, on the one hand, on samples of test pieces without calcite, which consisted only of the mixture of clays and feldspathic sand (PA test pieces), and, on the other hand, on samples of test pieces that contained $15 \%$ calcite particles, by weight, in addition to the same quantity and proportion of clays and feldspathic sand as the $P A$ test pieces ( $P A B$ test pieces). The DTA-TGA diagrams obtained with the two types of samples are shown superimposed in Figures 2 and 3. 
The DTA-TGA diagrams obtained in the tests conducted in air atmosphere and in $\mathrm{CO}_{2}$ atmosphere on calcite particles, identical to those contained in the test pieces, are shown in Figures 4 and 5, respectively, for comparative purposes.

All experiments were performed at an average total pressure of $101 \mathrm{kPa}$.

\section{Figures 2 to 5}

\subsubsection{Tests in air atmosphere}

In the DTA-TGA diagrams in Figure 2, corresponding to the tests conducted in air atmosphere, it may be observed that mass loss began as a result of clay dehydroxylation at about $714 \mathrm{~K}$ in the two studied samples ( $P A$ and $P A B$ ). The mass loss assignable to $\mathrm{CO}_{2}$ loss in sample $P A B$ began at $949 \mathrm{~K}$, whereas calcium carbonate decomposition started at a slightly higher temperature (975 K).

Comparison of these diagrams with those shown in Figure 5, corresponding to calcite particles, which were also obtained in air atmosphere, reveals significant differences. Indeed, the DTA diagram in Figure 5 displays a single peak, corresponding to calcite decomposition, whereas mass loss began abruptly in the TGA diagram, coinciding with DTA peak onset at $1012 \mathrm{~K}$ instead of 949 or $975 \mathrm{~K}$, as was the case in the test pieces. This difference in behaviour suggests that, in the $P A B$ test pieces, some type of interaction occurred between the $\mathrm{CaCO}_{3}$ that they contained and water vapour from clay dehydroxylation, which led to the formation of an intermediate compound that began to decompose, releasing $\mathrm{CO}_{2}$ and $\mathrm{H}_{2} \mathrm{O}$, at a lower temperature than that of calcium carbonate decomposition onset.

In support of this assumption, the work may be cited of Wang ${ }^{10}$ who, on studying calcite decomposition in the presence of water vapour, operating between 713 and $833 \mathrm{~K}$, interpreted the results by assuming that, in that temperature range, an intermediate compound is formed by chemisorption of water on specific active centres of calcium carbonate.

According to this researcher, the intermediate compound, of formula $\mathrm{CaCO}_{3}{ }^{*} \cdot \mathrm{H}_{2} \mathrm{O}$, decomposes parallel to $\mathrm{CaCO}_{3}$ according to the (reversible) reaction scheme:

$$
\mathrm{CaCO}_{3} * \mathrm{H}_{2} \mathrm{O}(\mathrm{s})=\mathrm{CaO}(\mathrm{s})+\mathrm{CO}_{2}(\mathrm{~g})+\mathrm{H}_{2} \mathrm{O}(\mathrm{g})
$$

The formation of this intermediate compound might explain the following: 
a) Mass loss was delayed between 773 and $949 \mathrm{~K}$ in the TGA diagram of the $P A B$ test piece with respect to that of the TGA diagram corresponding to the $P A$ test piece because part of the water vapour released during clay dehydroxylation was chemisorbed on the calcite.

b) There was a stretch in the TGA diagram of the $P A B$ test piece between 949 and $975 \mathrm{~K}$ in which mass loss appeared to stem from the decomposition of an intermediate compound (with $\mathrm{CO}_{2}$ and $\mathrm{H}_{2} \mathrm{O}$ release) rather than from decomposition of the initially contained calcite.

\subsubsection{Tests in $\mathrm{CO}_{2}$ atmosphere}

In the TGA diagram of Figure 3, corresponding to the tests conducted in $\mathrm{CO}_{2}$ atmosphere, the mass loss corresponding to clay dehydroxylation began practically at the same temperature in both test pieces as in the test performed in air atmosphere $(717 \mathrm{~K})$. However, the mass loss assignable to $\mathrm{CO}_{2}$ release in the sample of the $\mathrm{PAB}$ test piece began at $1058 \mathrm{~K}$, though the temperature at which calcium carbonate decomposition started was $1146 \mathrm{~K}$. In contrast, in the DTA-TGA diagram corresponding to calcite particles in $\mathrm{CO}_{2}$ atmosphere (Figure 4), no mass loss was observed till $1149 \mathrm{~K}$.

This result seems to confirm the possible formation of the intermediate compound mentioned above, which decomposed at a lower temperature than calcium carbonate would do in $\mathrm{CO}_{2}$ atmosphere, its decomposition being more delayed, in this case, than in the TGA diagram of Figure 2 owing to the presence of carbon dioxide in the gas phase, in accordance with the reversible reaction proposed in section 3.1.1.

In support of this assumption, it is interesting to consider the stretch in the TGA diagram corresponding to the sample of the $P A B$ test piece between $773 \mathrm{~K}$ and $1058 \mathrm{~K}$, in which a delay in mass loss may also be noted with respect to that of the $P A$ test piece. In addition, in this case as well, there was also a stretch between 1058 and $1146 \mathrm{~K}$ in which the mass loss appeared to be due to the decomposition of an intermediate compound containing carbon and water rather than to calcite decomposition.

Moreover, in the $P A B$ test piece, the mass loss due to $\mathrm{CO}_{2}$ release began at a quite lower temperature $(1058 \mathrm{~K})$ than the temperature at which it began in the sample of calcite particles (1149 K) in Figure 4. This might be caused by water vapour from clay hydroxylation partially 
or completely filling the pores of the sample of material, altering or cancelling out the influence that the $\mathrm{CO}_{2}$ present in the gas phase would have on the decomposition process of the calcium carbonate contained in the sample ${ }^{10}$.

On the other hand, according to the law of chemical equilibrium applied to the reversible calcium carbonate decomposition reaction:

$$
\mathrm{CaCO}_{3}(\mathrm{~s})=\mathrm{CaO}(\mathrm{s})+\mathrm{CO}_{2}(\mathrm{~g})
$$

and, in accordance with equation (8), which relates the dissociation pressure of this component to temperature, calcium carbonate decomposition should have started at $1168.5 \mathrm{~K}$, at the $\mathrm{CO}_{2}$ pressure $(101 \mathrm{kPa})$ at which the test was conducted.

In contrast, according to the TGA diagram of Figure 3, corresponding to the PAB test pieces, calcium carbonate decomposition occurred at $1058 \mathrm{~K}$ or $1146 \mathrm{~K}$; furthermore, according to the TGA diagram of Figure 4, decomposition of calcite particles began at $1149 \mathrm{~K}$.

This result suggests that, as it was observed on studying thermal decomposition of isolated calcite particles $^{8}$, some intermediate step occurred during this decomposition process, when it was conducted in $\mathrm{CO}_{2}$ atmosphere, which affected the equilibrium relationship at the solidgas interface, as noted in section 1.2.

\subsection{Series of experiments in the reactor}

Several series of experiments were conducted in the reactor under constant operating conditions, one of the operating variables (temperature or composition of the gas phase) being modified in each series. The experiments were carried out at six different test temperatures: $1115,1161,1170,1187,1205$, and $1238 \mathrm{~K}$ in a gas stream comprising different concentrations of air and $\mathrm{CO}_{2}\left(0,10,20,30,38,53,70\right.$, and $100 \% \mathrm{CO}_{2}$ by volume).

The results obtained have been plotted (as crosses, squares, circles, triangles, etc.) as conversion degree of the calcium carbonate contained in the test disks versus residence time in Figures 6 to 13. Each figure corresponds to one of the $\mathrm{CO}_{2}$ concentrations in the gas phase studied and contains the experimental results obtained at the six test temperatures.

Figures 6 to 13 


\subsubsection{Methodology used to test the fit of the proposed equation to the experimental results}

The methodology used to attempt to correlate the experimental results with equation (1) was the same as that used in the two previous papers ${ }^{3,4}$ and is summarised below.

In the lowest range of calcite conversion it was attempted to fit the experimental results to the following equation:

$$
\frac{d X}{d t}=\left(\frac{1}{L \cdot c_{B}^{0}}\right) \cdot\left[\frac{K_{C}-b \cdot c_{Q}^{G}}{\frac{K_{C} \cdot S_{S}}{k \cdot S_{1} \cdot(1-X)^{1 / 3}}}\right]
$$

which derives from the foregoing equation (1) when the overall process rate is only controlled by the rate of the chemical reaction step of $\mathrm{CaCO}_{3}$ decomposition.

In the highest range of calcite conversion it was attempted to fit the experimental results to equation (1), this being applied starting from a pair of values $\left(X=X_{02} ; t=t_{02}\right)$ chosen by trial and error from those resulting from the integration of equation (2), as described elsewhere ${ }^{3}$.

Under constant temperature conditions, it was possible to analytically integrate equations (1) and (2).

Integrating equation (2), starting from the boundary conditions $\left(X=0 ; t=t_{0}\right)$, gives:

$$
t=t_{0}+\frac{3 \cdot K_{C} \cdot S_{S} \cdot L \cdot C_{B}^{0}}{2 \cdot k \cdot S_{1} \cdot\left(K_{C}-b \cdot c_{Q}^{G}\right)} \cdot\left[1-(1-X)^{2 / 3}\right]
$$

where $t_{0}$ (induction time) is the time that the test disk took to reach the operating temperature in each experiment, which was determined from the experimental data in the form described ${ }^{3}$. Integrating equation (1), starting from the boundary conditions $\left(X=X_{02} ; t=t_{02}\right)$ as indicated above, gives:

$$
t=t_{02}+\frac{3 \cdot K_{C} \cdot S_{S} \cdot L \cdot C_{B}^{0}}{2 \cdot k \cdot S_{i} \cdot\left(K_{C}-b \cdot c_{Q}^{G}\right)} \cdot\left[\left(1-X_{02}\right)^{2 / 3}-(1-X)^{2 / 3}\right]+\frac{L^{2} \cdot C_{B}^{0}}{4 \cdot D_{e} \cdot\left(K_{C}-b \cdot c_{Q}^{G}\right)} \cdot\left[\frac{X^{2}}{2}-\frac{X_{02}^{2}}{2}\right]
$$


The conversion degree of the calcite in the test piece at which to switch from equation (3) to equation (4) to fit the experimental data $\left(X=X_{02}\right)$ depended on the operating conditions (test temperature and test disk thickness, initial porosity, and calcite content) ${ }^{4}$.

The values of $K_{c}$ were calculated, at each test temperature, from the equation:

$$
K_{c}=\frac{P_{Q}^{0}}{R T}
$$

In which $P_{Q}{ }_{Q}(\mathrm{kPa})$ was calculated from the Hill equation ${ }^{11}$ :

$$
P_{Q}^{0}=(0.1333) \cdot\left(10^{10.4022-87923 / T}\right)
$$

The $P_{Q}^{0}$ values obtained using equation (8), in the studied range of temperatures, practically coincided with those calculated using the equation proposed by Barin ${ }^{12}$.

The $\mathrm{CO}_{2}$ molar concentration in the gaseous phase $\left(C_{Q}^{G}\right)$ was calculated from the equation:

$$
C_{Q}^{G}=\frac{P \cdot y_{Q}^{G}}{R T}
$$

\subsubsection{Experiments conducted in air atmosphere}

In a previous paper ${ }^{3}$, under the same operating conditions and using test disks analogous to those studied here, it was found that the product $(k \cdot S)$ and the diffusivity $\left(D_{e}\right)$ in the above equations varied exponentially with test temperature and test disk initial porosity. The values of the product $(k \cdot S)$ were determined instead of those of $k$ because the reaction interface area (S) was not precisely known ${ }^{3}$.

Even though the test disks used in the present study were formed from the same raw materials according to the same method used in the previous papers, the properties of the present disks might vary slightly. This could affect the effectiveness of the equations proposed in those papers to predict the values of $D_{e}$ and of the product $(k \cdot S)$ corresponding to the test temperatures used in this study. 
To circumvent this problem, first, a series of experiments were conducted in air atmosphere at the six previously set test temperatures, with a view to directly obtaining the values of $D_{e}$ and of the product $(k \cdot S)$ that would subsequently be substituted in equations (3) and (4) in order to attempt to correlate the results of the experiments carried out in the presence of $\mathrm{CO}_{2}$ at the same test temperatures. The results obtained in this series of experiments are plotted in Figure 6.

In order to apply the methodology proposed above (section 3.2.1), the values of $C_{B}^{0}=2.925$ $\mathrm{kmol} / \mathrm{m}^{3}, S_{s}=0.00125 \mathrm{~m}^{2}$, and $L=0.007 \mathrm{~m}$, corresponding to the characteristics of the test disks used, were substituted in equations (3) and (4), setting $c_{Q}{ }^{G}=0$.

Equation (3) was then applied, at each test temperature, to the experimental results corresponding to the lowest values of $X$ using different pairs of values of the product $(k \cdot S)$ and induction time $\left(t_{0}\right)$, until the curve that best fitted to the experimental results was obtained by trial and error.

The values of $(k \cdot S)$ and $t_{0}$ obtained in the best fit, at each test temperature, together with the corresponding values of $K_{C}$ calculated from equations (7) and (8), are shown in Table 1.

The values of $(k \cdot S)$ obtained at the two lowest test temperatures (1115 and $1161 \mathrm{~K})$ practically coincided with those calculated using the correlation proposed in the previous study $^{3}$. However, the values obtained at the highest temperatures were slightly higher. Using the new values, the following relationship was obtained between the values of $(k \cdot S)$ and the test temperature:

$$
k \cdot S_{1}=3.06 \cdot \exp \left(-\frac{131560}{8.314 \cdot T}\right)
$$

The corresponding $X=f(t)$ representations obtained on applying equation (3), using the values of the product $(k \cdot S)$ and of $t_{0}$ shown in Table 1, have been plotted in Figure 6 (solid lines) together with the experimental data.

On the other hand, for the highest range of conversion degrees, it was attempted to fit the experimental results with equation (4), using the corresponding values of the product $(k \cdot S)$ obtained from equation (10). 
Equation (4) was applied at each test temperature, starting from a pair of values $\left(X=X_{02} ; t=\right.$ $t_{02}$ ) chosen by trial and error from those resulting from the integration of equation (3), applied to the corresponding operating conditions. Different pairs of values of $X_{02}$ and $t_{02}$ were tested, until the best fit of equation (4) to the highest range of experimental data of $X$ was found.

The values of $X_{02}$ and of $t_{02}$, as well as those of $D_{\Theta}$ resulting from the best fits obtained on applying equation (4) to the second sections of the experimental data plots, at each test temperature, are also shown in Table 1.

\section{Table 1}

The values obtained for $D_{\Theta}$ at each test temperature, were of the same order as those calculated from the equation proposed in a previous paper $^{3}$ for test disks with the same initial porosity as those used in this study $\left(\varepsilon_{0}=0.229\right)$. That equation is of the form:

$$
D_{e}=0.01767 \cdot \exp \left(-\frac{45857}{R T}\right)
$$

The $X=f(t)$ curves obtained at each test temperature, resulting from the best fit of equation (4) are also plotted in Figure 6 (dashed lines).

\subsubsection{Experiments conducted in $\mathrm{CO}_{2}$ atmosphere}

The possibility was studied, first, of applying equations (3) and (4) to correlate the results obtained in the most extreme conditions, i.e. those obtained in the experiments conducted at the six test temperatures operating in carbon dioxide atmosphere (Figure 13).

For this, after the values of $L, C_{B}{ }^{0}$, and $S_{\theta}$ as well as those corresponding to the operating variables $K_{C}, k \cdot S, c_{Q}{ }^{G}$, and $D_{\Theta}$ calculated from equations (7) to (11), had been substituted in equations (3) and (4), different values of $b$ were tested to determine by trial and error the value of parameter $b$ that provided the best fit of equations (3) and (4) to the experimental data.

Surprisingly when equation (3) was applied to the data corresponding to the lowest conversion range, the best fit to the results was obtained for $b=0$ at all test temperatures.

On the other hand, when the data corresponding to the experiments conducted with different concentrations of $\mathrm{CO}_{2}$ at each test temperature were plotted in the form $X$ versus $t$, the stretch 
corresponding to the lowest conversion range coincided for all test $\mathrm{CO}_{2}$ concentrations. By way of example, Figures 14 and 15 show the corresponding graphic representations at the two extreme temperatures studied (1115 and $1238 \mathrm{~K}$ ).

These results indicate that, in the period corresponding to the lowest conversion range, the specific $\mathrm{CO}_{2}$ concentration in the gas phase $\left(c_{Q}{ }^{G}\right)$ did not influence the thermal decomposition kinetics of the calcium carbonate contained in the test pieces.

As suggested in section 3.1, this behaviour might have been due, as the process unfolded, to clay dehydroxylation beginning before calcium carbonate decomposition (see Figure 2), causing water vapour from the first reaction to completely fill the pores of the test piece before the second reaction started. Under these circumstances, calcium carbonate decomposition at the reaction interface would occur in the presence of water vapour, leading the system to behave, during the first process stage, as if it unfolded in the absence of $\mathrm{CO}_{2}$.

In order to confirm this assumption, a series of experiments were conducted after previously treating the test pieces for 30 minutes at $1025 \mathrm{~K}$ in $\mathrm{CO}_{2}$ atmosphere to remove physically adsorbed water and the hydroxylation water contained in the clays. The test pieces were then placed in the reactor, operating in $\mathrm{CO}_{2}$ atmosphere at the chosen temperature $(1158 \mathrm{~K})$, and data logging was started. The results obtained are plotted in Figure 16, in the form $X$ versus $t$, together with the corresponding data obtained at the same temperature in air atmosphere and in $\mathrm{CO}_{2}$ atmosphere, in these last two cases operating in the form described in section 2.2. As may be observed, the points representing the results corresponding to the experiment conducted with the previously dehydroxylated test pieces are clearly separated from those of the test pieces treated as in the rest of the experiments and are shifted towards the abscissa axis. This shows that calcium carbonate decomposition developed more slowly in the previously dehydroxylated test pieces because, as they contained no water in their pores, the presence of $\mathrm{CO}_{2}$ in the gas phase influenced process kinetics from the beginning of the experiment.

In contrast, Figure 14 shows that, at $1161 \mathrm{~K}$, the composition of the gaseous phase influenced the process rate in the highest range of conversion values because, in this stretch, the slope of 
the $X-t$ plot decreased when the $\mathrm{CO}_{2}$ concentration increased. This influence diminished when the test temperature was raised, evidenced by the increasing length of the stretch in which the $\mathrm{CO}_{2}$ concentration did not influence process kinetics as the test temperature rose.

Indeed, as may be observed in Figure 15, at the highest test temperature (1238 K), the first period in which the $\mathrm{CO}_{2}$ concentration in the gaseous phase did not influence the process kinetics reached a conversion degree of 0.98 . This suggests that, at this temperature, the calcium carbonate decomposition rate was higher than the dehydroxylation rate, so that practically all the calcium carbonate contained in the test piece decomposed in the presence of steam.

The stretch of the $X-t$ curves obtained by applying equation (3), corresponding to the experiments performed at the test temperatures, setting $b=0$, have been plotted as solid lines, together with the experimental data, in Figure 13.

Given that, at the lowest test temperatures, after removal of all the hydroxylation water in the clays, the $\mathrm{CaCO}_{3}$ decomposition step could continue to limit the overall process rate, it was attempted to continue to apply equation (3) to correlate a second stretch of conversion, assigning a value other than zero to parameter $b$.

First, it was attempted to use a value of $b$ calculated from equation (12):

$$
b=\left(1.096+0.190 \cdot y_{Q}^{G}\right) \cdot \exp \left[\frac{-602.3}{T}\right]
$$

where $y_{Q}{ }^{G}$ is the $\mathrm{CO}_{2}$ molar fraction in the gaseous phase.

This equation was proposed in a previous paper ${ }^{8}$ in which the decomposition, in $\mathrm{CO}_{2}$ atmosphere, of calcite particles, of the same nature as those introduced into the test pieces used in this research, was studied.

Equation (3) was applied again in a second stretch, starting from a pair of values $\left(X=X_{02} ; t=\right.$ $t_{02}$ ) chosen by trial and error from those resulting from the first application of equation (3), using a value of $b$ calculated from equation (12). 
The resulting stretches of $X-t$ curves obtained by thus applying equation (3) are plotted as dashed lines, together with the experimental data, also in Figure 13.

Finally, starting from a pair of values $\left(X=X_{03} ; t=t_{03}\right)$, chosen by trial and error from those resulting from the second application of equation (3), equation (4) was applied in the highest range of the conversion degree, using the same value of parameter $b$ that had been used in equation (3) when this was applied to the second stretch.

In this last case the methodology described in section 3.2.1 was used, substituting in equation (4) the values of the operating variables used on applying equation (3), as well as the values of $D_{e}$ and $c_{Q}{ }^{G}$ corresponding to each test temperature.

The $X$ - $t$ curves obtained by applying equation (4) have been plotted as dotted lines, together with the experimental data, also in Figure 13.

The respective pairs of values of $X_{02}$ and $t_{02}$ resulting from the best fits obtained with equation (3) and the pairs of values of $X_{03}$ and $t_{03}$ resulting from the best fits obtained with equation (4), together with the corresponding values of $T$ and $t_{0}$, as well as the values of $b,(k \cdot S), K_{C}$, $C_{Q}{ }^{G}$, and $D_{e}$ used in each case, are shown in Table 2.

\section{Table 2}

It may be observed that the lines representing the pairs of $X-t$ values, calculated by applying the above equations to the three stretches being considered, fitted very well to the experimental data obtained at the test temperatures of 1238,1208 , and $1187 \mathrm{~K}$ and fitted quite well (up to $X=0.8$ ) to the data obtained at the test temperatures of 1170 and $1161 \mathrm{~K}$.

The above all appears to confirm the validity of the proposed model when the decomposition process unfolded in $\mathrm{CO}_{2}$ atmosphere at a temperature of $1161 \mathrm{~K}$ or higher. This temperature was slightly higher than that at which calcium carbonate decomposition began, in $\mathrm{CO}_{2}$ atmosphere, in the test pieces according to the DTA-TGA diagram of Figure 3. 
At $1115 \mathrm{~K}$, equation (3) fitted well to the experimental data only in a short stretch of the conversion degree (up to $X=0.3$ ). However, this temperature was $31 \mathrm{~K}$ lower than the temperature $(1146 \mathrm{~K})$ below which, according to the DTA-TGA diagram of Figure 3, calcite decomposed in $\mathrm{CO}_{2}$ atmosphere.

It is therefore very likely that, in that short range of conversion degrees (up to $X=0.3$ ), calcium carbonate decomposed because it was in the presence of steam that filled the pores of the test piece. Once the dehydroxylation phase had ended, however, it would not be possible for the calcium carbonate to decompose at this temperature. Therefore, the mass loss of the piece, starting from which the conversion degree for values larger than 0.3 was calculated, could only be due to decomposition of some intermediate compound, as noted in section 3.1

Perhaps for this reason, at a test temperature of $1115 \mathrm{~K}$, it was only possible to correlate the experimental data corresponding to the two last stretches with equations (3) and (4), when a value of $b=0.36$ was used instead of the value of 0.75 obtained from equation (12).

\subsubsection{Experiments conducted in mixtures of air and $\mathrm{CO}_{2}$}

In order to verify the effectiveness of equations (3) and (4) for correlating the experimental data obtained in mixtures of air and carbon dioxide with different compositions, the methodology described above was applied after substituting in these equations the corresponding values of the operating variables $\left(L, c_{B}^{0}, S_{\theta} K_{C}, k \cdot S, D_{\theta}, C_{Q}{ }^{G}\right.$, and $\left.b\right)$. These values, which were calculated from equations (7) to (12), are shown in Tables 2 and 3.

The results obtained in the experiments carried out with mixtures containing less than $38 \%$ $\mathrm{CO}_{2}$, by volume, except the series corresponding to test temperature $1115 \mathrm{~K}$ and $38 \% \mathrm{CO}_{2}$, were correlated using the methodology described in section 3.2.1, using equations (3) and (4), considering only two stretches.

The results obtained in the experiments conducted in mixtures of air and $\mathrm{CO}_{2}$ containing $38 \%$ or more $\mathrm{CO}_{2}$, by volume, were correlated using the methodology described in section 3.2.3, considering three stretches.

The respective pairs of values of $X_{02}$ and $t_{02}$ resulting from the best fit obtained with equation (3) and the pairs of values of $X_{03}$ and $t_{03}$ resulting from the best fit obtained with equation (4), 
together with the corresponding values of $T$ and $t_{0}$, as well as the values of $b,\left(k \cdot S_{)}\right), K_{C}, c_{Q}{ }^{G}$, and $D_{e}$ used in each case, are shown in Tables 3 and 4.

The $X-t$ curves that best fitted to the experimental data, obtained by sequentially applying equations (3) and (4), using the methodology described in section 3.1, have been plotted as solid lines and dashed lines respectively, together with the experimental data, in Figures 7 to 9.

\section{Table 3}

The $X-t$ curves that best fitted to the experimental data in the tests with mixtures of $38 \%$ or more $\mathrm{CO}_{2}$, by volume, obtained using the methodology described in section 3.2.3, considering three stretches, have been plotted as solid lines, dashed lines, and dotted lines, respectively, together with the experimental data, in Figures 10 to 12.

\subsubsection{Considerations regarding parameter $b$}

The values of parameter $b$ used to fit the experimental data with equations (3) and (4) were analogous to those obtained when the thermal decomposition of calcite particles, identical to those added to the raw materials mixture used in this research, was studied in the presence of carbon dioxide ${ }^{8}$.

These results strengthen the hypothesis, put forward in that paper, that an equilibrium law like the one indicated in section 1.2.b) was also obeyed in the present case at the test piece-gas interface. As set out in that paper, this equilibrium law may be a consequence of an adsorption phenomenon of $\mathrm{CO}_{2}$ on the $\mathrm{CaO}$ resulting from calcite decomposition.

In addition, according to certain researchers, the clays used to form the test disks in this study, which were of an illitic-kaolinitic nature ${ }^{13}$, as well as some of the components (calcium silicates and aluminosilicates such as wollastonite, gehlenite, and anorthite), which form during and after firing ${ }^{1}$, also appear to have the ability to physically adsorb $\mathrm{CO}_{2}{ }^{9,14}$. 


\section{Conclusions}

The equation proposed in a previous paper, modified in this study by assuming that the relationship between the molar concentrations of $\mathrm{CO}_{2}$ on both sides of the gas-solid interface was conditioned by an equilibrium law, has been successfully used to correlate the results obtained on studying the thermal decomposition of the calcium carbonate contained in ceramic test pieces when the process was conducted in the presence of mixtures of air and $\mathrm{CO}_{2}$.

Using the methodology proposed in that paper, the equations put forward satisfactorily fitted the results obtained in the entire studied temperature range $(1115-1238 \mathrm{~K})$ when the $\mathrm{CO}_{2}$ content in the gaseous phase was less than $38 \%$ by volume. However, when the $\mathrm{CO}_{2}$ concentration in the gaseous phase was $38 \%$ or more, by volume, it was necessary to slightly modify the methodology used in order to improve the fit of the proposed equations to the experimental data.

During the first stretch of the process, in which the overall process rate was controlled by the rate of the chemical reaction step, the proposed equation only fitted well to the experimental data when it was assumed that the presence of carbon dioxide in the gaseous phase did not influence the process kinetics. This seems to be because, during the time period corresponding to this stretch, the steam resulting from clay dehydroxylation completely fills the pores of the test piece. Under these circumstances, the calcium carbonate decomposes in the presence of steam. Therefore, the carbon dioxide concentration in the gaseous phase, in contact with the test piece, does not influence the decomposition reaction development.

At the highest test temperature $(1238 \mathrm{~K})$, this first stretch reached a conversion degree of 0.98 in the entire range of studied $\mathrm{CO}_{2}$ concentrations.

In industrial kilns used to manufacture porous wall tiles, the $\mathrm{CO}_{2}$ concentrations in the gas phase are typically less than $15 \%$ (by volume) and temperature range in which calcite decomposition develops lies between 1130 and $1175 \mathrm{~K}$. The results of this study indicate that, in this range of operating conditions, the carbon dioxide concentration in the gaseous phase hardly influenced the process kinetics. 
The knowledge obtained in this research, as well as the equations and methodology proposed, have been successfully used to optimise the firing cycle of industrial kilns used to manufacture porous ceramic wall tiles.

\section{Acknowledgements}

The authors thank the Instituto de la Mediana y Pequeña Empresa de Valencia (IMPIVA) of the Generalitat Valenciana for its financial help. They are also grateful for the support of ERDF funds from the European Union. Project reference IMIDIC/2007/102.

\section{Appendix}

\section{A.2. Rate equation of the overall process}

If it is assumed that the equilibrium law governing the relationship between $C_{Q S}^{S}$ and $c_{Q S}^{G}$ at the test disk-gas interface is of the form:

$$
c_{Q S}^{S}=b \cdot c_{Q S}^{G}
$$

(where $b$ is an equilibrium constant at the interface ${ }^{8}$ ), from equation (A.11) and equation (A.13) in the Appendix of the previous paper $^{1}$ one obtains:

$$
-R_{\mathrm{B}}=\frac{K_{C}-c_{Q i}^{S}}{\frac{K_{C}}{k \cdot S_{i} \cdot(1-X)^{1 / 3}}}=\frac{c_{\mathrm{Qi}}^{\mathrm{S}}-c_{\mathrm{QS}}^{\mathrm{S}}}{\frac{\mathrm{L} \cdot \mathrm{X}}{4 \cdot \mathrm{S}_{\mathrm{S}} \cdot \mathrm{D}_{\mathrm{e}}}}=\frac{c_{\mathrm{QS}}^{\mathrm{G}}-c_{\mathrm{Q}}^{\mathrm{G}}}{\frac{1}{2 \cdot \mathrm{S}_{\mathrm{S}} \cdot \mathrm{k}_{\mathrm{G}}}}=\frac{b \cdot c_{Q S}^{G}-b \cdot c_{Q}^{G}}{\frac{b}{2 \cdot S_{S} \cdot k_{G}}}
$$

Applying the property of proportions to the second, third, and fifth member of the foregoing equation then yields:

$$
-R_{\mathrm{B}}=\frac{K_{C}-b \cdot c_{\mathrm{Q}}^{\mathrm{G}}}{\frac{\mathrm{K}_{\mathrm{C}}}{\mathrm{k} \cdot \mathrm{S}_{\mathrm{i}} \cdot(1-X)^{1 / 3}}+\frac{\mathrm{L} \cdot \mathrm{X}}{4 \cdot \mathrm{S}_{\mathrm{S}} \cdot \mathrm{D}_{\mathrm{e}}}+\frac{\mathrm{b}}{2 \cdot \mathrm{S}_{\mathrm{S}} \cdot \mathrm{k}_{\mathrm{G}}}}
$$

which would, in this case, represent the overall process rate relating to component $B\left(\mathrm{CaCO}_{3}\right)$. 
Equation (A.15) from the previous paper ${ }^{1}$, which represents the law of conservation of matter applied to component $B$, may be written in the form:

$$
R_{\mathrm{b}}=c_{\mathrm{B}}^{0} \cdot \mathrm{S}_{\mathrm{S}} \cdot \mathrm{L} \cdot\left(-\frac{\mathrm{dX}}{\mathrm{dt}}\right)
$$

The two foregoing equations yield:

$$
\frac{d X}{d t}=\left(\frac{1}{L \cdot c_{B}^{0}}\right) \cdot\left[\frac{K_{C}-b \cdot c_{Q}^{G}}{\frac{K_{C} \cdot S_{S}}{k \cdot S_{1} \cdot(1-X)^{1 / 3}}+\frac{L \cdot X}{4 \cdot D_{e}}+\frac{b}{2 \cdot k_{G}}}\right]
$$

Since a sufficiently high gas rate with respect to the test disks was used in the experiments conducted in mixtures of air and $\mathrm{CO}_{2}$ and the other experiments were conducted in $\mathrm{CO}_{2}$ atmosphere, the third term of the denominator of the second member, which represents the resistance of the $\mathrm{CO}_{2}$ transfer step from the test disk surface to the gas phase, can be neglected. This gives:

$$
\frac{d X}{d t}=\left(\frac{1}{L \cdot C_{B}^{0}}\right) \cdot\left[\frac{K_{C}-b \cdot c_{Q}^{G}}{\frac{K_{C} \cdot S_{S}}{k \cdot S_{1} \cdot(1-X)^{1 / 3}}+\frac{L \cdot X}{4 \cdot D_{e}}}\right]
$$

which is the equation used to fit to the experimental data.

\section{Nomenclature}

Symbol

Name (Units)

$b \quad$ equilibrium constant in equation (A.1)

$c_{B}^{0} \quad$ initial molar concentration of $\mathrm{CaCO}_{3}$ in the test disk $\left(\mathrm{kmol} / \mathrm{m}^{3}\right)$

$c_{Q}^{G} \quad$ molar concentration of $\mathrm{CO}_{2}$ in the gas phase $\left(\mathrm{kmol} / \mathrm{m}^{3}\right)$

$D_{e} \quad$ effective overall diffusivity of $\mathrm{CO}_{2}$ through the solid reacted layer $\left(\mathrm{m}^{2} / \mathrm{min}\right)$

$k \quad$ rate constant of the direct reaction $\left(\mathrm{kmol} /\left(\mathrm{m}^{2} \cdot \mathrm{min}\right)\right.$

$K_{c} \quad$ chemical equilibrium constant $\left(\mathrm{kmol} / \mathrm{m}^{3}\right)$ of the reaction 
$k_{G} \quad$ mass transfer coefficient $(\mathrm{m} / \mathrm{min})$

$L \quad$ test disk initial thickness (m)

$P_{Q}^{0} \quad$ dissociation pressure of calcium carbonate at temperature $\mathrm{T}$ (atm)

$R \quad$ universal gas constant $\left[8.317 \mathrm{kPa} \cdot \mathrm{m}^{3} /(\mathrm{kmol} \cdot \mathrm{K})\right]$

S reaction interface area $\left(\mathrm{m}^{2}\right)$

$S_{S} \quad$ cross-sectional area of the test disk $\left(\mathrm{m}^{2}\right)$

$t \quad$ residence time $(\min )$

$T \quad$ temperature (K)

$X \quad \mathrm{CaCO}_{3}$ degree of conversion

$y_{Q}{ }^{G} \quad \mathrm{CO}_{2}$ molar fraction in the gaseous phase.

\section{Greek letters}

$\varepsilon_{0} \quad$ test disk initial porosity

\section{References}

1. Amorós, J. L., Escardino, A., Sanchez, E. and Zaera, F., Stabilità delle dimensioni nelle piastrelle porose monocotte. Ceram. Inf., 1993, 324, 56-67.

2. Amorós, J.L. et al. Defectos de fabricación de pavimentos y revestimientos cerámicos. [Castellón]: AICE-Instituto de Tecnología Cerámica, 1991.

3. Escardino, A., García-Ten, J., Feliu, C. and Moreno, A., Calcium carbonate thermal decomposition in white-body wall tile during firing. I. Kinetic study. J. Eur. Ceram. Soc. 2010, 30 (10), 1989-2001.

4. Escardino, A., García-Ten, J., Feliu, C. and Gozalbo, A., Calcite thermal decomposition in white-body wall tile during firing. II Influence of body thickness and calcite content. Ceram. Int. 2012, 38, 3141-3147.

5. Beruto,D., Botter, R. and Searcy, A.W., Thermodynamics and kinetics of carbon dioxide chemisorption on calcium oxide. J. Phys. Chem. 1984, 88, 4052-4055. 
6. Khinast, J., Krammer, G.F., Brunner, C. and Staudinger, G., Decomposition of limestone: The influence of $\mathrm{CO}_{2}$ and particle size on the reaction rate. Chem. Eng. Sci., 1996, 51 (4), 623-634.

7. García-Labiano, F., Abad, A., de Diego, L. F., Gayán, P. and Adánez, J., Calcination of calcium-based sorbents at pressure in a broad range of $\mathrm{CO}_{2}$ concentrations. Chem. Eng. Sci., 2002, 57 (13), 2381-2393.

8. Escardino, A., García-Ten, J., Feliu, C., Cantavella, V. and Saburit, A., Kinetic study of the thermal decomposition process of calcite particles in air and $\mathrm{CO}_{2}$ atmosphere. J. Ind. Eng. Chem. Manuscript Number: JIEC-D-12-00150 (accepted for publication $03 / 11 / 2012)$.

9. Aylmore, L. A. G., Gas sorption in clay mineral systems. Clays Clay Miner., 1974, 22, $175-183$.

10. Wang, Y. and Thomson, W.J., The effects of steam and carbon dioxide on calcite decomposition using dynamic X-Ray diffraction. Chem. Eng. Sci., 1995, 50 (9), 13731382.

11. Hill, K.J., Winter, E.R.S., Thermal dissociation pressure of calcium carbonate. J. Phys. Chem., 1956, 60, 1361-1362.

12. Barin, I. Thermochemical data of pure substances. Weinheim, VCH, 1989.

13. Beltrán, V., Sánchez, E., García-Ten, J. and Gines, F., Materias primas empleadas en la fabricación de baldosas de pasta blanca en España. Técnica Cerámica, 1996, 241, 114 128.

14. Aylmore, L.A.G., Sills, I.D. and Quirk, J.P., Surface area of homoionic illite and montmorillonite clay minerals as measured by the sorption of nitrogen and carbon dioxide. Clays Clay Miner., 1970, 18 (2), 91-96. 
Table 1. Values of $t_{0,}(k \cdot S i), X_{02}$, and $t_{02}$ obtained in the best fits of equations (3) and (4), together with the corresponding values of $T, K_{\sigma}$ and $D_{e}\left(S_{S}=0.00125 \mathrm{~m}^{2} ; \varepsilon_{0}=0.229 ; L=0.007 \mathrm{~m}\right)$. Experiments conducted in air atmosphere.

\begin{tabular}{|c|c|c|c|c|c|c|}
\hline $\begin{array}{c}T \\
(\mathrm{~K})\end{array}$ & $\begin{array}{c}K_{\boldsymbol{c}} \cdot 10^{3} \\
\left(\mathrm{kmol} / \mathrm{m}^{3}\right)\end{array}$ & $\begin{array}{c}\left(\mathrm{k} \cdot \mathrm{S}_{\mathrm{i}}\right) \cdot 10^{6} \\
(\mathrm{kmol} / \mathrm{min})\end{array}$ & $\begin{array}{c}t_{0} \\
(\mathrm{~min})\end{array}$ & $\boldsymbol{X}_{02}$ & $\begin{array}{c}t_{02} \\
(\mathrm{~min})\end{array}$ & $\begin{array}{c}D_{e} \cdot 10^{4} \\
\left(\mathrm{~m}^{2} / \mathrm{min}\right)\end{array}$ \\
\hline 1115 & 4.7 & 2.10 & 0.0 & 0.800 & 11.7 & 1.25 \\
\hline 1161 & 9.3 & 3.70 & 1.0 & 0.735 & 7.10 & 1.50 \\
\hline 1168 & 10.6 & 4.12 & 0.7 & 0.770 & 6.50 & 1.58 \\
\hline 1187 & 13.4 & 5.00 & 1.1 & 0.795 & 6.20 & 1.70 \\
\hline 1206 & 17.0 & 6.13 & 1.1 & 0.840 & 5.50 & 1.82 \\
\hline 1238 & 26.0 & 8.00 & 1.3 & 0.99 & 5.60 & 2.05 \\
\hline
\end{tabular}

Table 2. Values of $t_{0,}, b, X_{02}, t_{02}, X_{03}$, and $t_{03}$ obtained in the best fits of equation (3), first and second stretch, and of equation (4), together with the corresponding values of $T$ and $c_{Q}^{G}\left(S_{S}=0.00125 \mathrm{~m}^{2}\right.$; $\varepsilon_{0}=0.229 ; \mathrm{L}=0.007 \mathrm{~m}$ ). Experiments conducted in $\mathrm{CO}_{2}$ atmosphere.

\begin{tabular}{|c|c|c|c|c|c|c|c|}
\hline $\begin{array}{c}\mathbf{T} \\
(\mathrm{K})\end{array}$ & $\begin{array}{c}c_{Q}^{G} \cdot 10^{3} \\
\left(\mathrm{kmol} / \mathrm{m}^{3}\right)\end{array}$ & $\begin{array}{c}\boldsymbol{t}_{0} \\
(\mathrm{~min})\end{array}$ & $\mathbf{b}$ & $\boldsymbol{X}_{02}$ & $\begin{array}{c}\boldsymbol{t}_{02} \\
(\mathrm{~min})\end{array}$ & $\boldsymbol{X}_{03}$ & $\begin{array}{c}\boldsymbol{t}_{03} \\
(\mathbf{m i n})\end{array}$ \\
\hline 1115 & 11,9 & 1.0 & 0.36 & 0.33 & 6.3 & 0.52 & 50 \\
\hline 1161 & 10.6 & 1.5 & 0.765 & 0.46 & 5.3 & 0.70 & 24.4 \\
\hline 1168 & 10.4 & 1.2 & 0.77 & 0.54 & 5.2 & 0.65 & 9.3 \\
\hline 1187 & 10.3 & 1.4 & 0.78 & 0.58 & 4.8 & 0.70 & 7.0 \\
\hline 1206 & 10,2 & 1.5 & 0,78 & 0.65 & 4.8 & 0.90 & 8.2 \\
\hline 1238 & 9.96 & 1.3 & 0.79 & 0.95 & 5.2 & 0.98 & 5.6 \\
\hline
\end{tabular}


Table 3. Values of $t_{0,}, b, X_{02}, t_{02}, X_{03}$ and $t_{03}$ obtained in the best fits of equation (3), first and second stretch, and of equation (4), together with the corresponding values of $T$ and $y_{Q}{ }^{G} \quad\left(S_{S}=0.00125\right.$ $\mathrm{m}^{2} ; \varepsilon_{0}=0.229 ; \mathrm{L}=0.007 \mathrm{~m}$ ). Experiments conducted in an air- $\mathrm{CO}_{2}$ mixture with a $y_{Q}{ }^{G}$ value of 0.38 or higher.

\begin{tabular}{|c|c|c|c|c|c|c|c|}
\hline $\begin{array}{c}\mathbf{T} \\
(\mathrm{K})\end{array}$ & $y_{Q}{ }^{G}$ & $\begin{array}{c}t_{0} \\
(\mathrm{~min})\end{array}$ & $\mathbf{b}$ & $X_{02}$ & $\begin{array}{c}t_{02} \\
(\mathrm{~min})\end{array}$ & $X_{03}$ & $\begin{array}{c}t_{03} \\
(\mathbf{m i n})\end{array}$ \\
\hline 1115 & 0.38 & 0.9 & 0.680 & 0.27 & 4.5 & 0.30 & 5,50 \\
\hline 1115 & 0.53 & 1.0 & 0.715 & 0.36 & 6.1 & 0.45 & 17.5 \\
\hline 1115 & 0.70 & - & - & - & - & - & - \\
\hline 1161 & 0.38 & 1.3 & 0.695 & 0.41 & 4.40 & 0.70 & 8.23 \\
\hline 1161 & 0.53 & 1.7 & 0.710 & 0.43 & 4.98 & 0.46 & 5.40 \\
\hline 1161 & 0.70 & 1.4 & 0.725 & 0.42 & 4.75 & 0.50 & 6.60 \\
\hline 1168 & 0.38 & 1.1 & 0.700 & 0.53 & 4.80 & 0.75 & 7.30 \\
\hline 1168 & 0.53 & 1.3 & 0.715 & 0.51 & 5.00 & 0.67 & 6.30 \\
\hline 1168 & 0.70 & 1.5 & 0.730 & 0.52 & 5.10 & 0.60 & 6.50 \\
\hline 1187 & 0.38 & 1.0 & 0.705 & 0.84 & 6.40 & 0.85 & 5.50 \\
\hline 1187 & 0.53 & 0.9 & 0.720 & 0.85 & 6.40 & 0.90 & 7.00 \\
\hline 1187 & 0.70 & 1.4 & 0.740 & 0.83 & 6.70 & 0.85 & 7.50 \\
\hline 1206 & 0.38 & 1.0 & 0.710 & 0.90 & 5.90 & 0.93 & 6.30 \\
\hline 1206 & 0.53 & 1.1 & 0.730 & 0.90 & 6.00 & 0.95 & 6,60 \\
\hline 1206 & 0.70 & 1.3 & 0.750 & 0.90 & 6,25 & 0.91 & 6.30 \\
\hline 1238 & 0.38 & 1.2 & 0.720 & 0.94 & 4.95 & 0.98 & 5.33 \\
\hline 1238 & 0.53 & 1.2 & 0.740 & 0.96 & 5.30 & 0.98 & 5.52 \\
\hline 1238 & 0.70 & 1.2 & 0.760 & 0.96 & 5.20 & 0.99 & 5.60 \\
\hline
\end{tabular}


Table 4. Values of $t_{0,} b, X_{02}, t_{02}, X_{03}$ and $t_{03}$ obtained in the best fits of equations (3) and (4), together with the corresponding values of $T$ and $y_{Q}{ }^{G}\left(S_{S}=0.00125 \mathrm{~m}^{2} ; \varepsilon_{0}=0.229 ; L=0.007 \mathrm{~m}\right)$. Experiments conducted in an air- $\mathrm{CO}_{2}$ mixture with a $y_{Q}{ }^{G}$ value of 0.30 or lower.

\begin{tabular}{|c|c|c|c|c|c|c|c|}
\hline $\begin{array}{c}\mathrm{T} \\
(\mathrm{K})\end{array}$ & ${y_{Q}{ }^{G}}$ & $\begin{array}{c}\boldsymbol{t}_{0} \\
(\mathrm{~min})\end{array}$ & $b$ & $X_{02}$ & $\begin{array}{c}t_{02} \\
(\mathrm{~min})\end{array}$ & $X_{03}$ & $\begin{array}{c}t_{03} \\
(\mathrm{~min})\end{array}$ \\
\hline 1115 & 0.10 & 0.6 & 0.650 & 0.62 & 9.3 & - & - \\
\hline 1115 & 0.20 & 0.9 & 0.660 & 0.48 & 7.3 & - & - \\
\hline 1115 & 0.30 & 1.0 & 0.670 & 0.35 & 5.7 & 0.40 & 7.0 \\
\hline 1161 & 0.10 & 0.9 & 0.667 & 0.81 & 7.9 & - & - \\
\hline 1161 & 0.20 & 1.4 & 0.677 & 0.82 & 8.5 & - & - \\
\hline 1161 & 0.30 & 1.3 & 0.688 & 0.71 & 7,1 & - & - \\
\hline 1168 & 0.10 & 0.9 & 0.670 & 0.82 & 7.3 & - & - \\
\hline 1168 & 0.20 & 0.9 & 0.680 & 0.80 & 7.4 & - & - \\
\hline 1168 & 0.30 & 1.1 & 0.690 & 0.77 & 6.9 & - & - \\
\hline 1187 & 0.10 & 1.0 & 0.675 & 0.86 & 6.6 & - & - \\
\hline 1187 & 0.20 & 1.0 & 0.685 & 0.86 & 6.6 & - & - \\
\hline 1187 & 0.30 & 1.0 & 0.695 & 0.87 & 6.7 & - & - \\
\hline 1206 & 0.10 & 1.0 & 0.680 & 0.92 & 6.1 & - & - \\
\hline 1206 & 0.20 & 1.2 & 0.690 & 0.90 & 6.1 & - & - \\
\hline 1206 & 0.30 & 1.1 & 0.700 & 0.92 & 6.2 & - & - \\
\hline 1238 & 0.10 & 1.2 & 0.690 & 0.96 & 5.2 & - & - \\
\hline 1238 & 0.20 & 1.3 & 0.700 & 0.96 & 5.3 & - & - \\
\hline 1238 & 0.30 & 1.2 & 0.710 & 0.97 & 5.2 & - & - \\
\hline
\end{tabular}

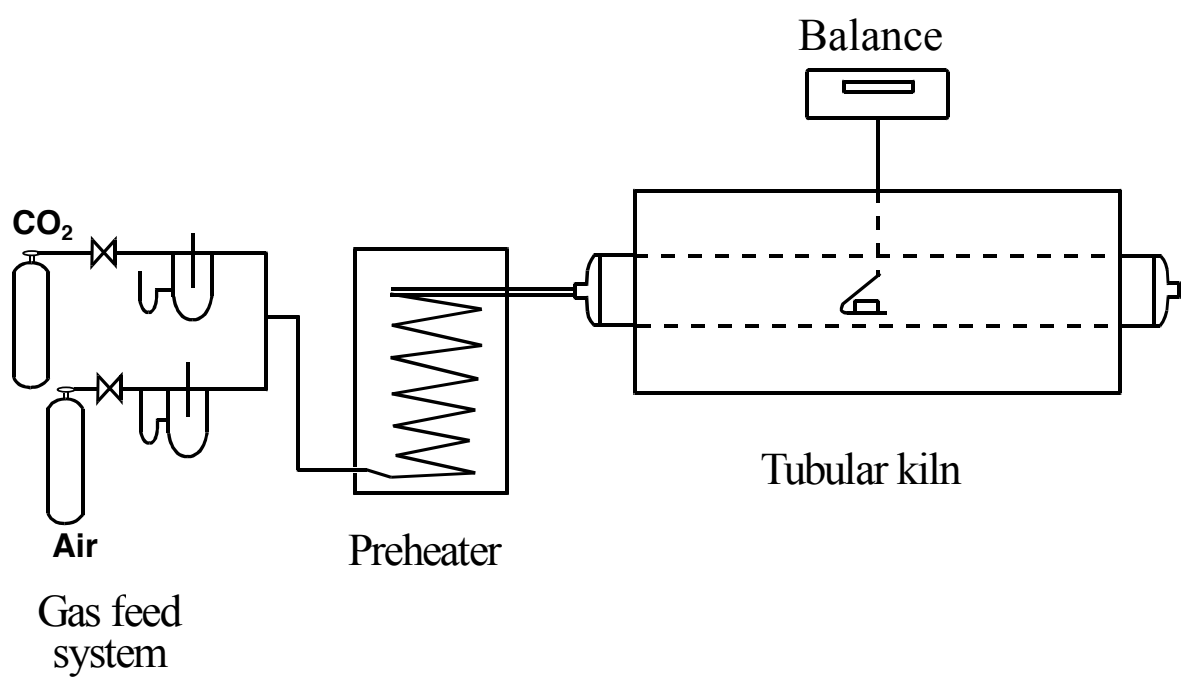

Figure 1 Experimental assembly 


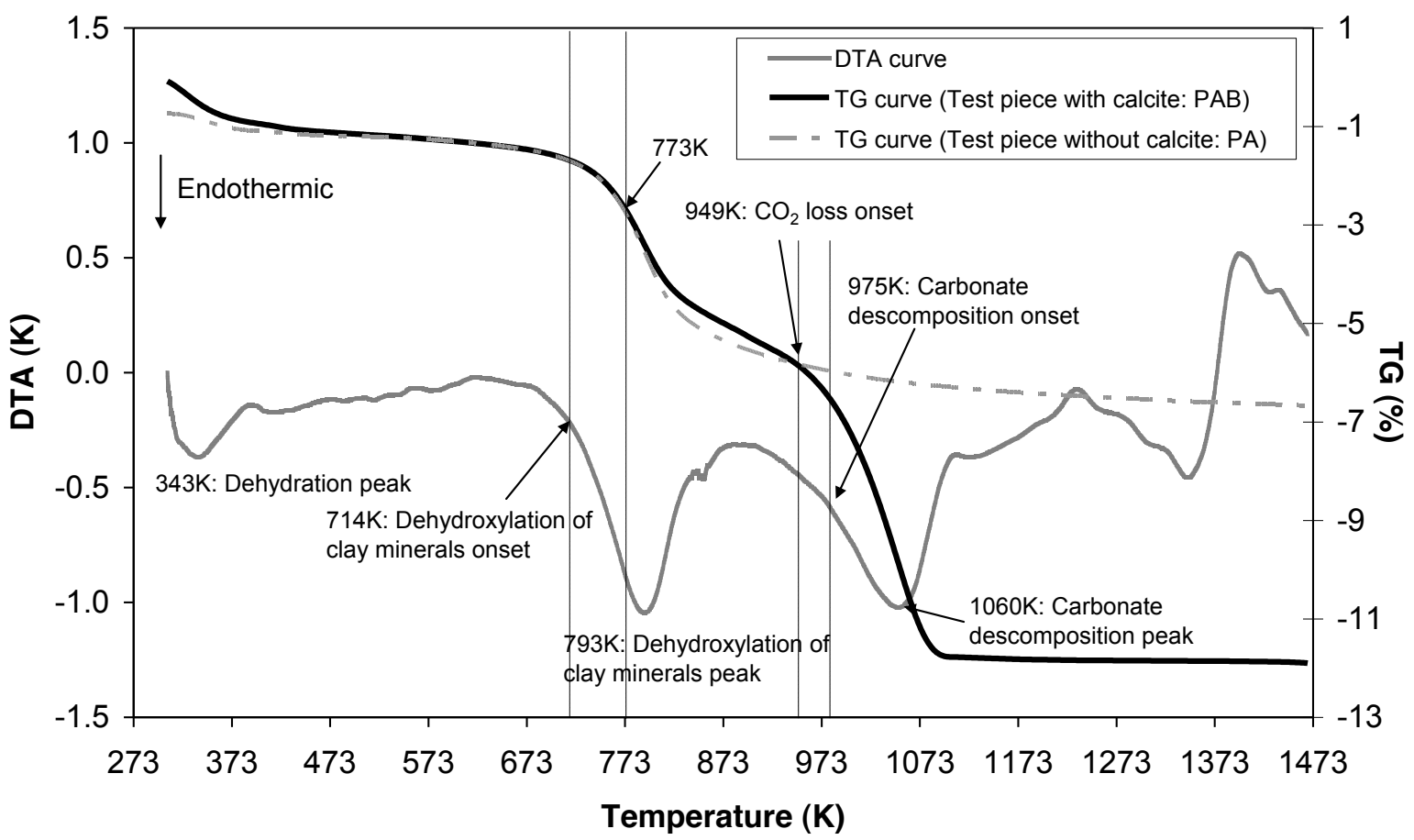

Figure 2 DTA-TGA diagram of a milled test disk sample containing calcite in air atmosphere

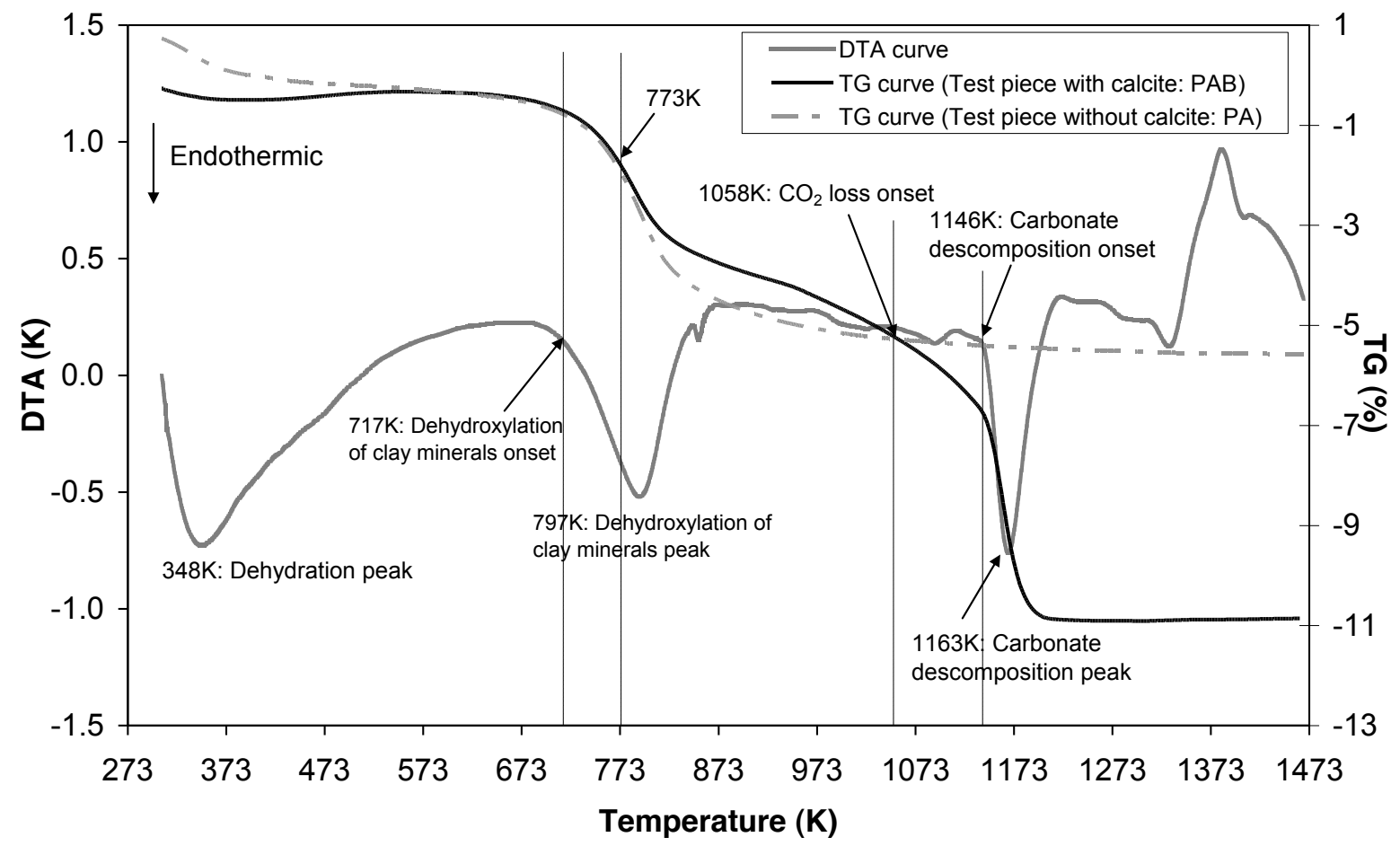

Figure 3 DTA-TGA diagram of a milled test disk sample containing calcite in $\mathrm{CO}_{2}$ atmosphere. 


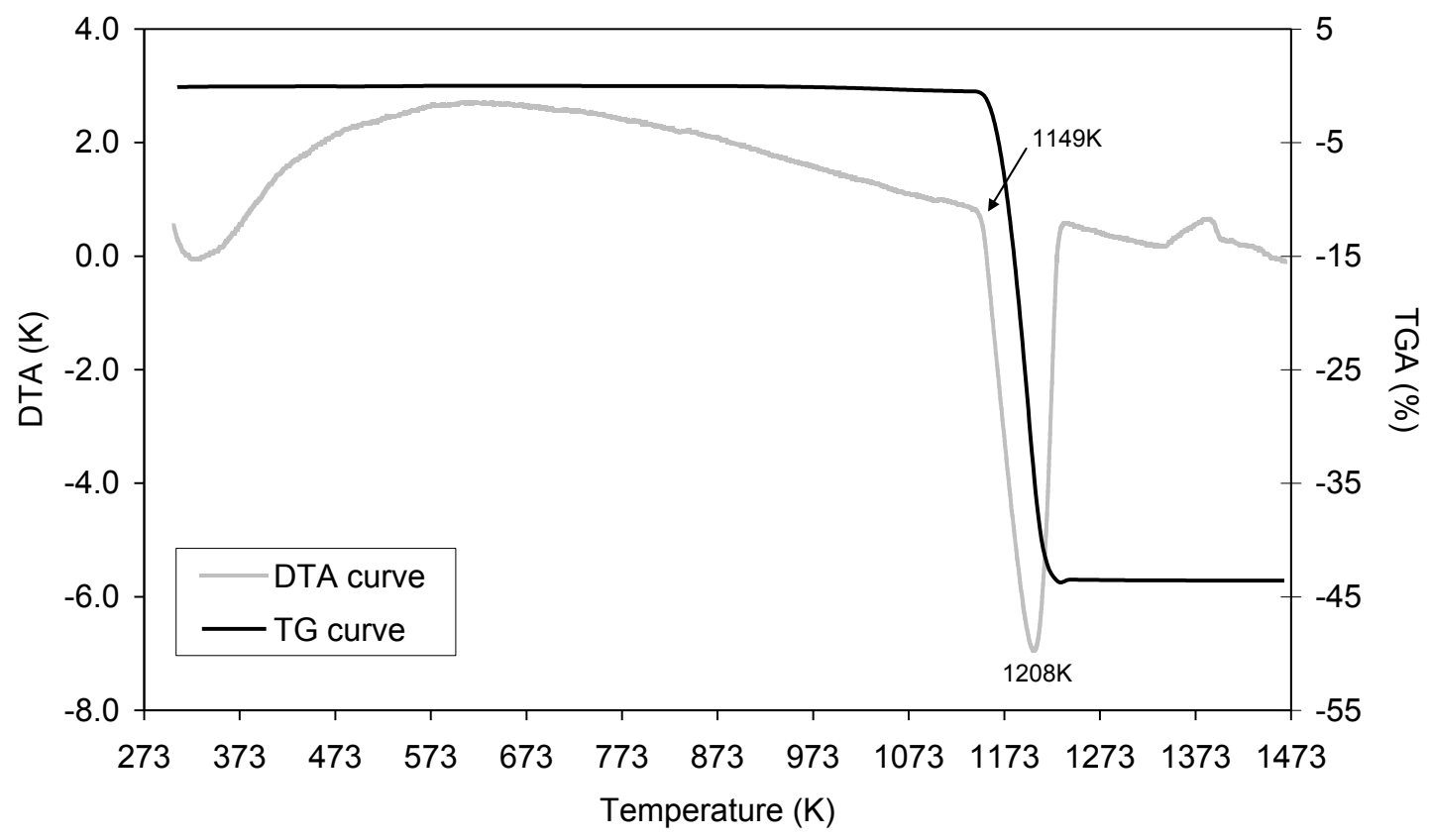

Figure 4. DTA-TGA diagram of the calcite particles in $\mathrm{CO}_{2}$ atmosphere.

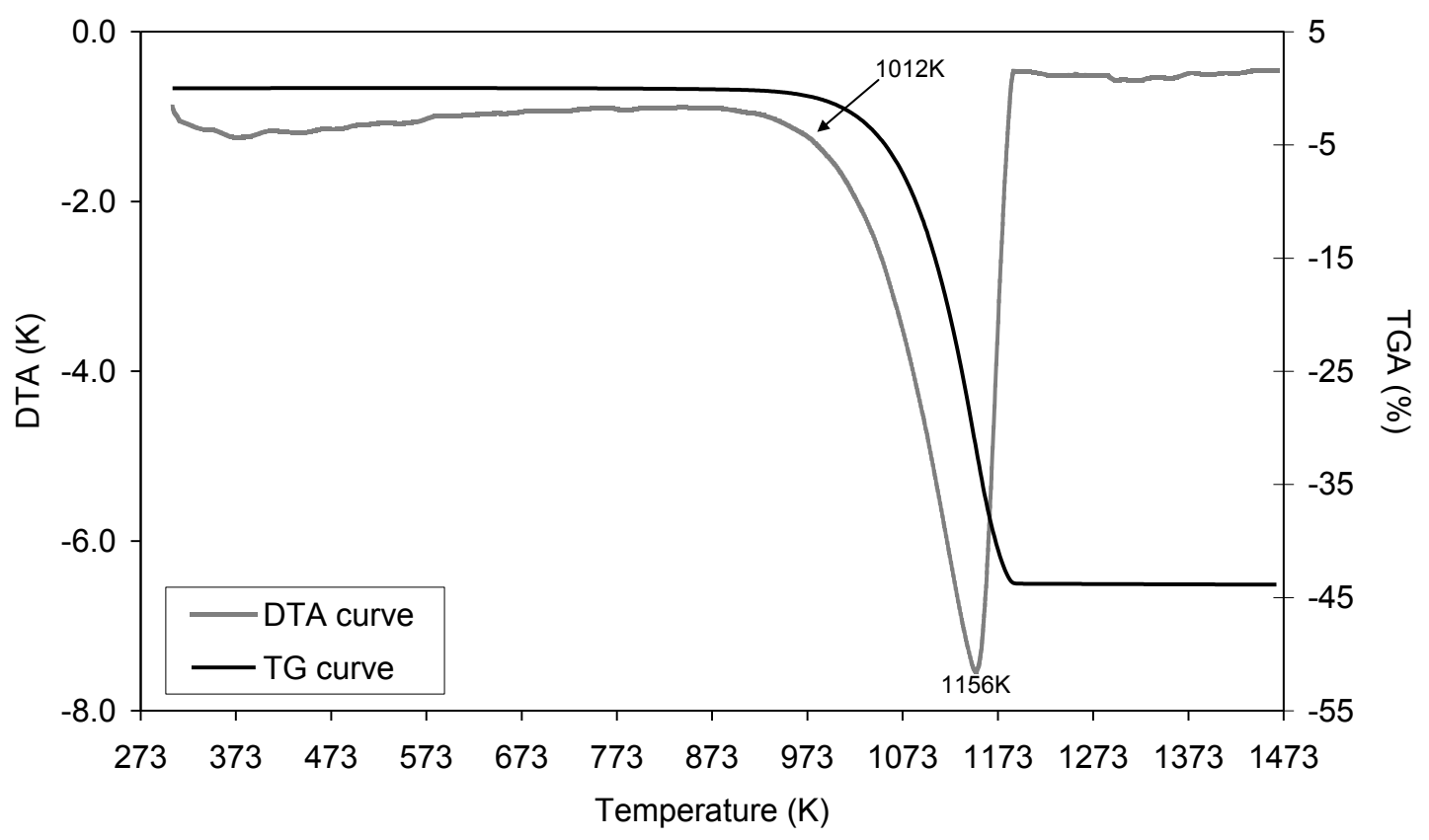

Figure 5. DTA-TGA diagram of the calcite particles in air atmosphere. 


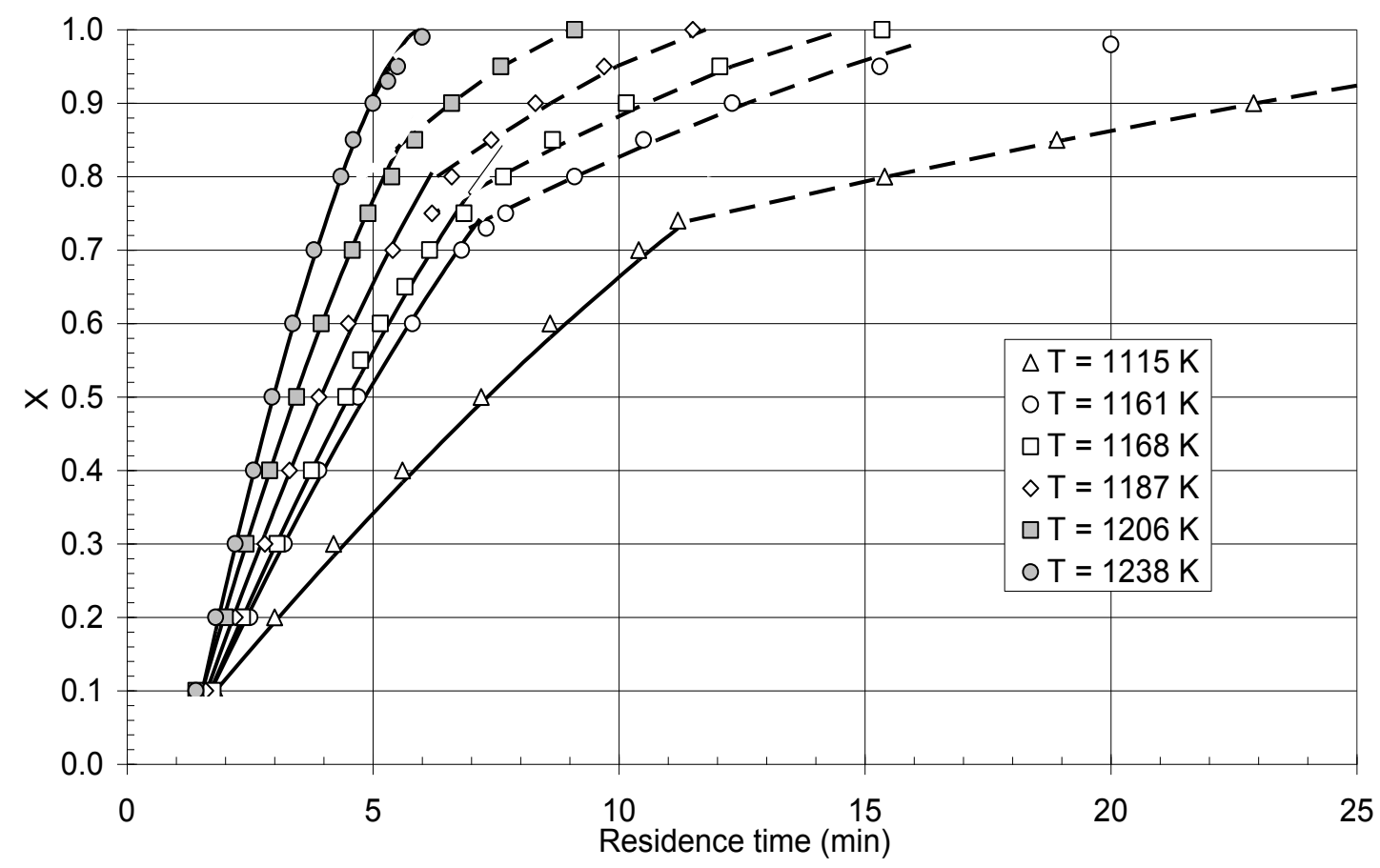

Figure 6 Fit of the experimental data obtained in air atmosphere at different temperatures to equations (3) (solid lines) and (4) (dashed lines). $\varepsilon_{0}=0.229 ; c_{B}^{0}=$ $2.925 \mathrm{kmol} / \mathrm{m}^{3} ; L=0.007 \mathrm{~m}$.

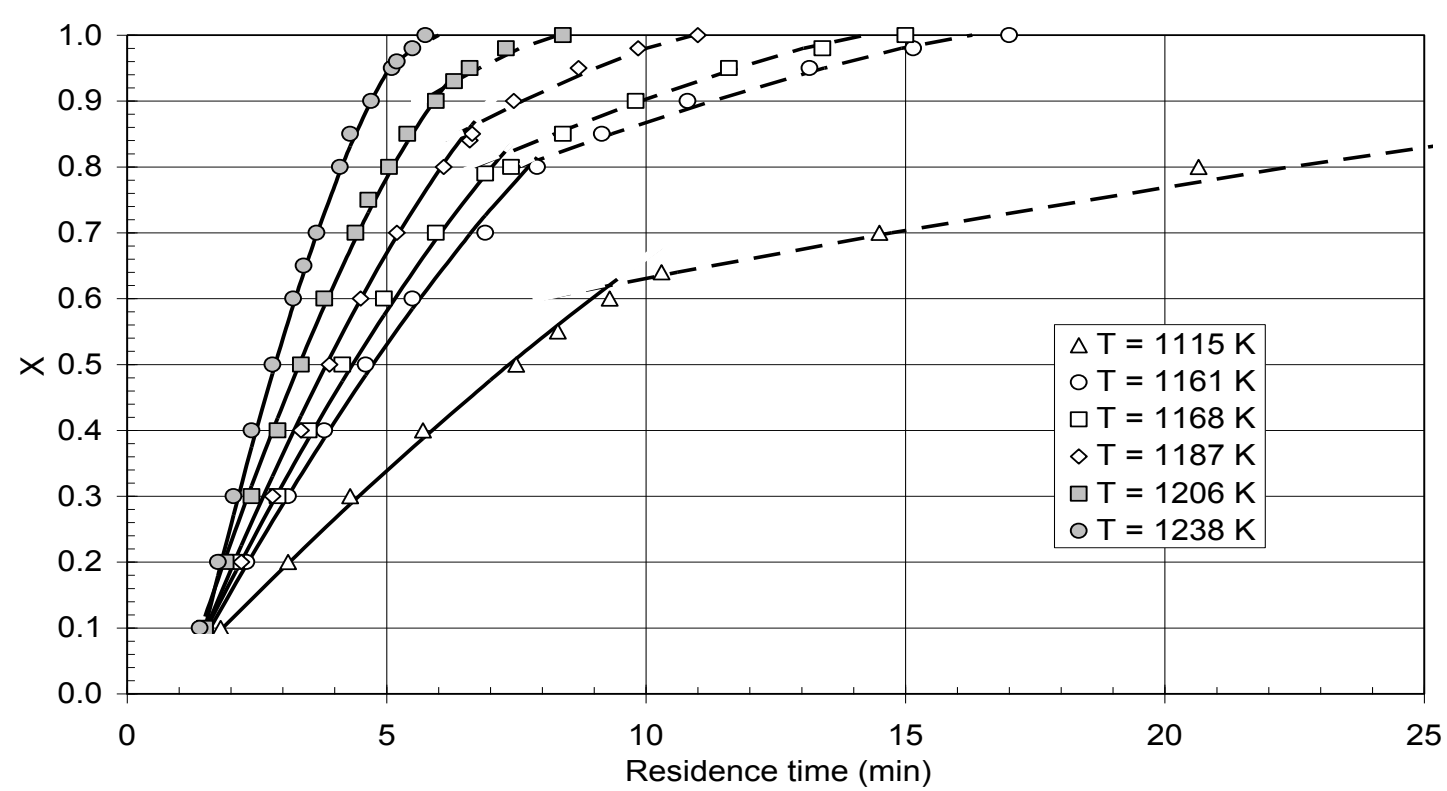

Figure 7 Fit of the experimental data obtained in a gas stream containing $10 \% \mathrm{CO}_{2}$ by volume at different temperatures to equations (3) (solid lines) and (4) (dashed lines). $\varepsilon_{0}=0.229 ; c_{B}^{0}=2.925 \mathrm{kmol} / \mathrm{m}^{3} ; L=0.007 \mathrm{~m}$. 


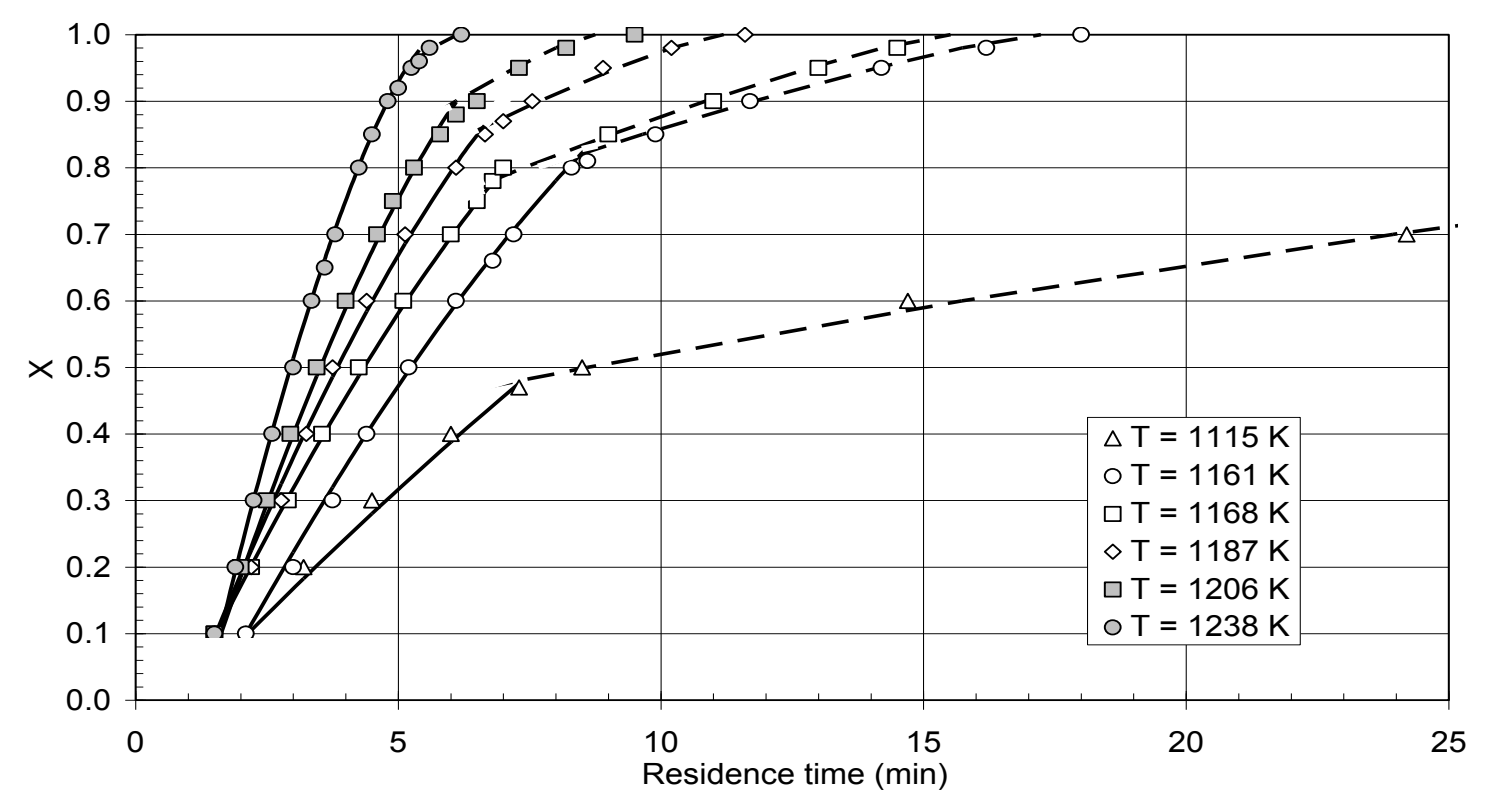

Figure 8 Fit of the experimental data obtained in a gas stream containing $20 \% \mathrm{CO}_{2}$ by volume at different temperatures to equations (3) (solid lines) and (4) (dashed lines). $\varepsilon_{0}=$ $0.229 ; c_{B}^{0}=2.925 \mathrm{kmol} / \mathrm{m}^{3} ; L=0.007 \mathrm{~m}$.

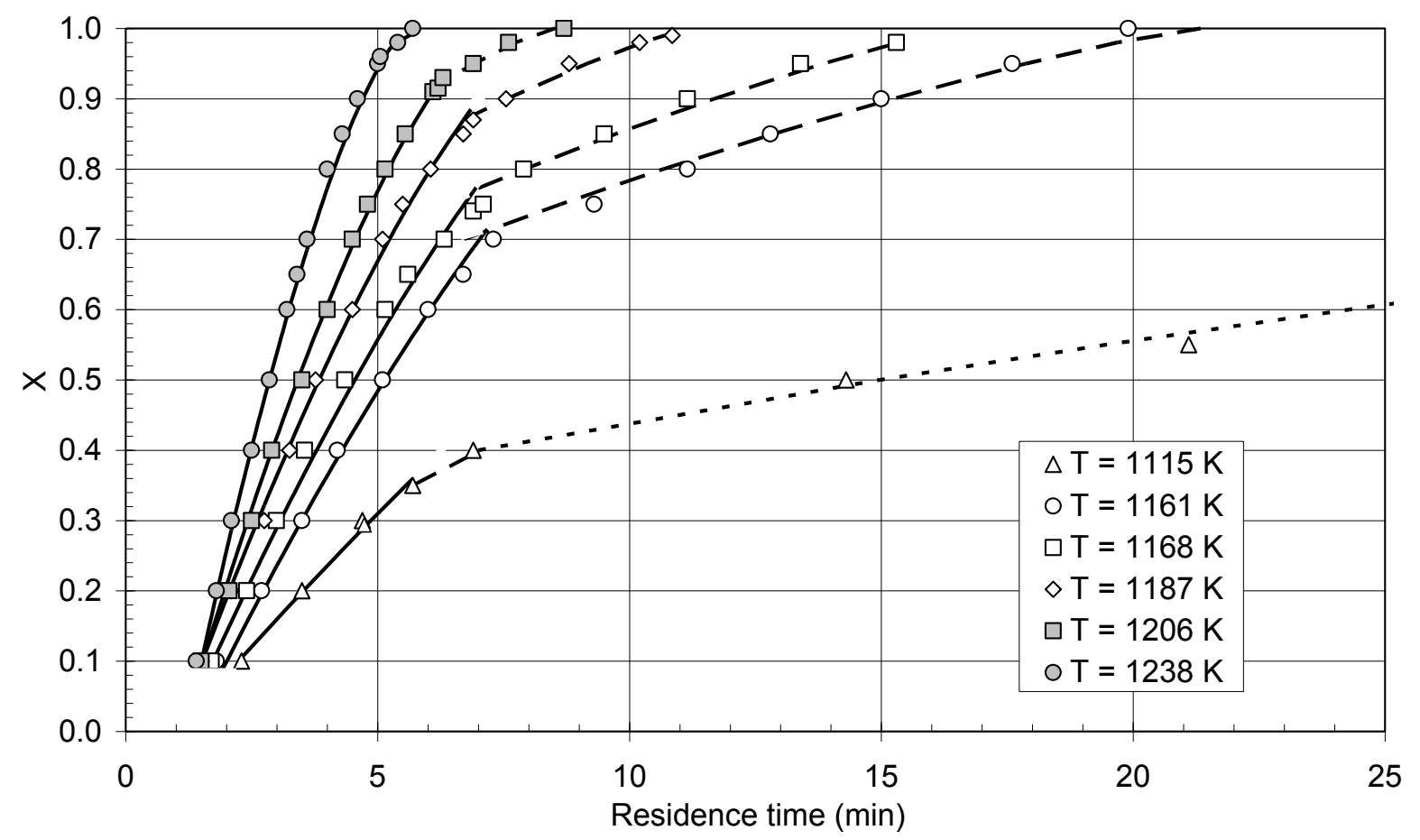

Figure 9 Fit of the experimental data obtained in a gas stream containing $30 \% \mathrm{CO}_{2}$ by volume at different temperatures to equations (3) (solid lines) and (4) (dashed lines). $\varepsilon_{0}=0.229 ; c_{B}^{0}=2.925 \mathrm{kmol} / \mathrm{m}^{3} ; L=0.007 \mathrm{~m}$. 


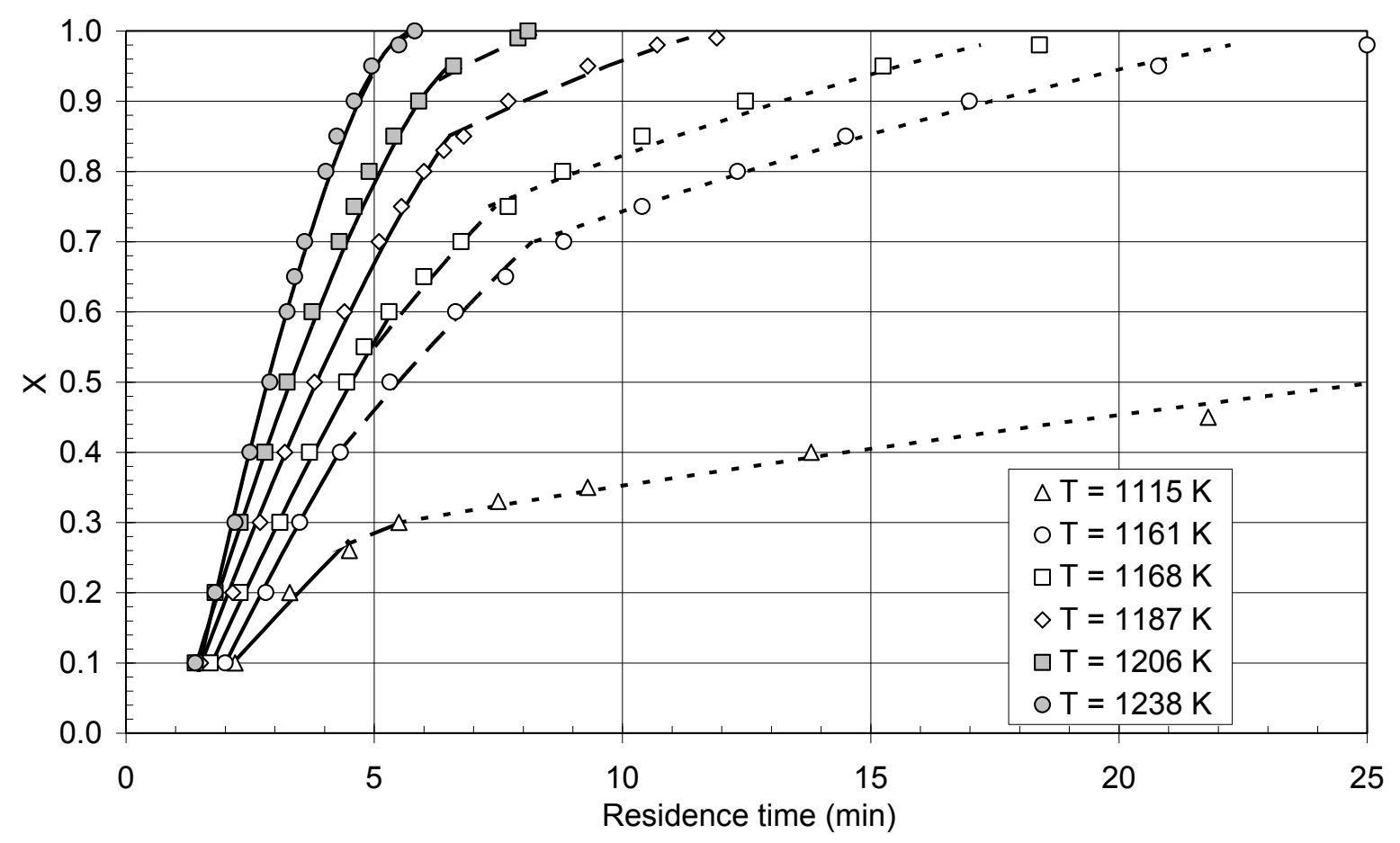

Figure 10 Fit of the experimental data obtained in a gas stream containing $38 \% \mathrm{CO}_{2}$ by volume at different temperatures to equations (3) (solid and dashed lines) and (4) (dottedlines). $\varepsilon_{0}=0.229 ; c_{B}^{0}=2.925 \mathrm{kmol} / \mathrm{m}^{3} ; L=0.007 \mathrm{~m}$.

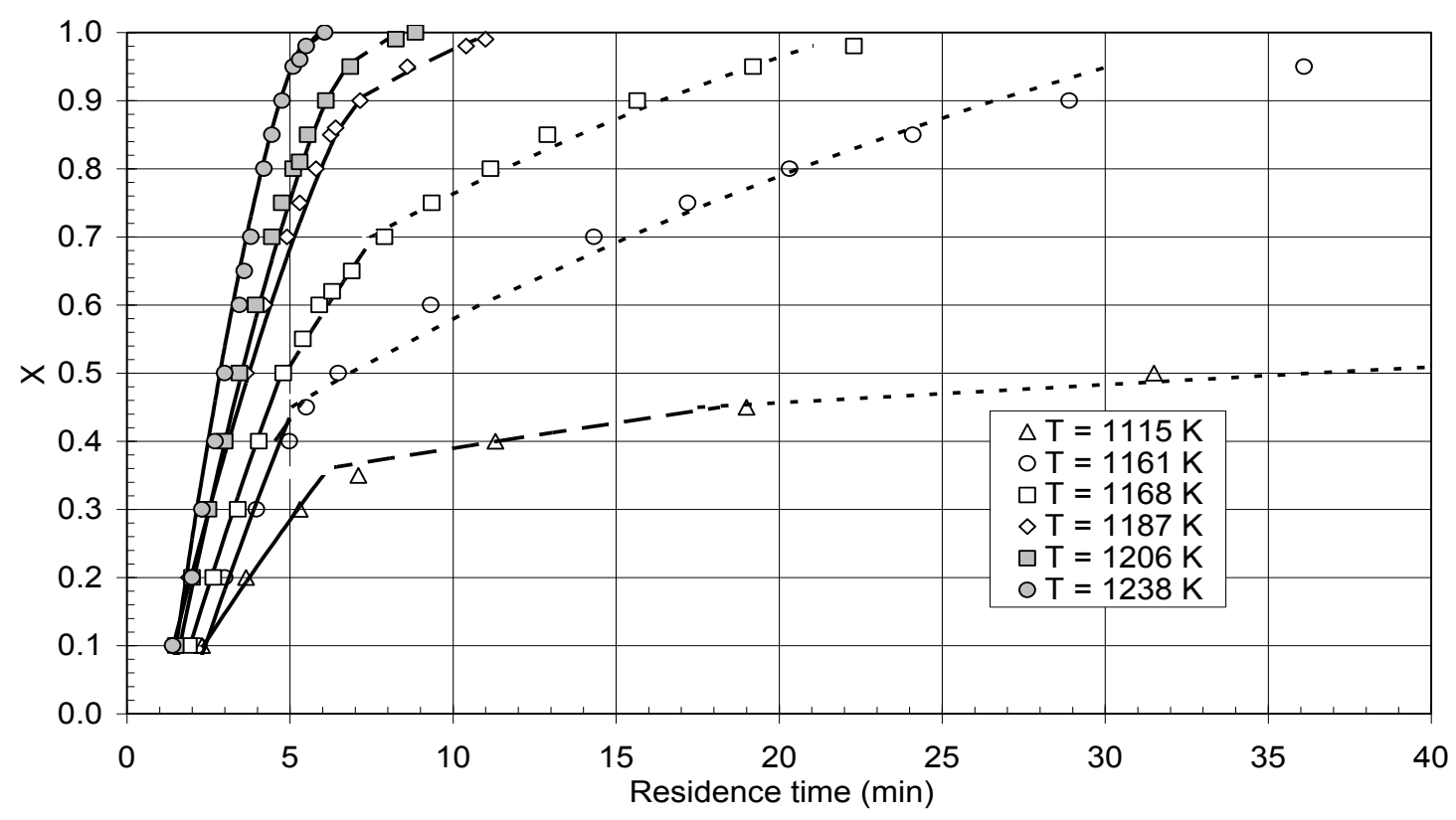

Figure 11 Fit of the experimental data obtained in a gas stream containing $53 \% \mathrm{CO}_{2}$ by volume at different temperatures to equations (3) (solid and dashed lines) and (4) (dottedlines). $\varepsilon_{0}=0.229 ; c_{B}^{0}=2.925 \mathrm{kmol} / \mathrm{m}^{3} ; L=0.007 \mathrm{~m}$ 


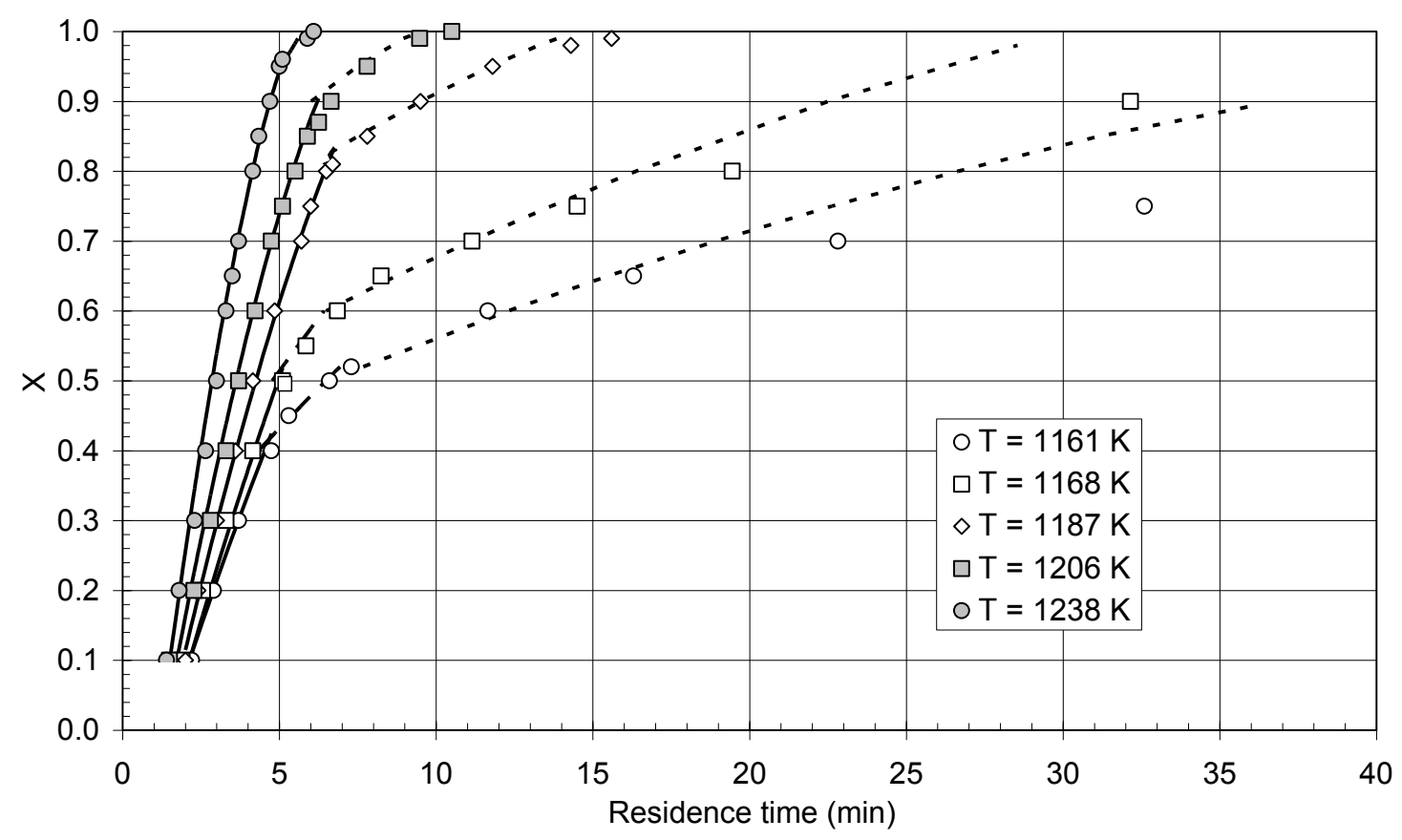

Figure 12 Fit of the experimental data obtained in a gas stream containing $70 \% \mathrm{CO}_{2}$ by volume at different temperatures to equations (3) (solid and dashed lines) and (4) (dottedlines). $\varepsilon_{0}=0.229 ; c_{B}^{0}=2.925 \mathrm{kmol} / \mathrm{m}^{3} ; L=0.007 \mathrm{~m}$

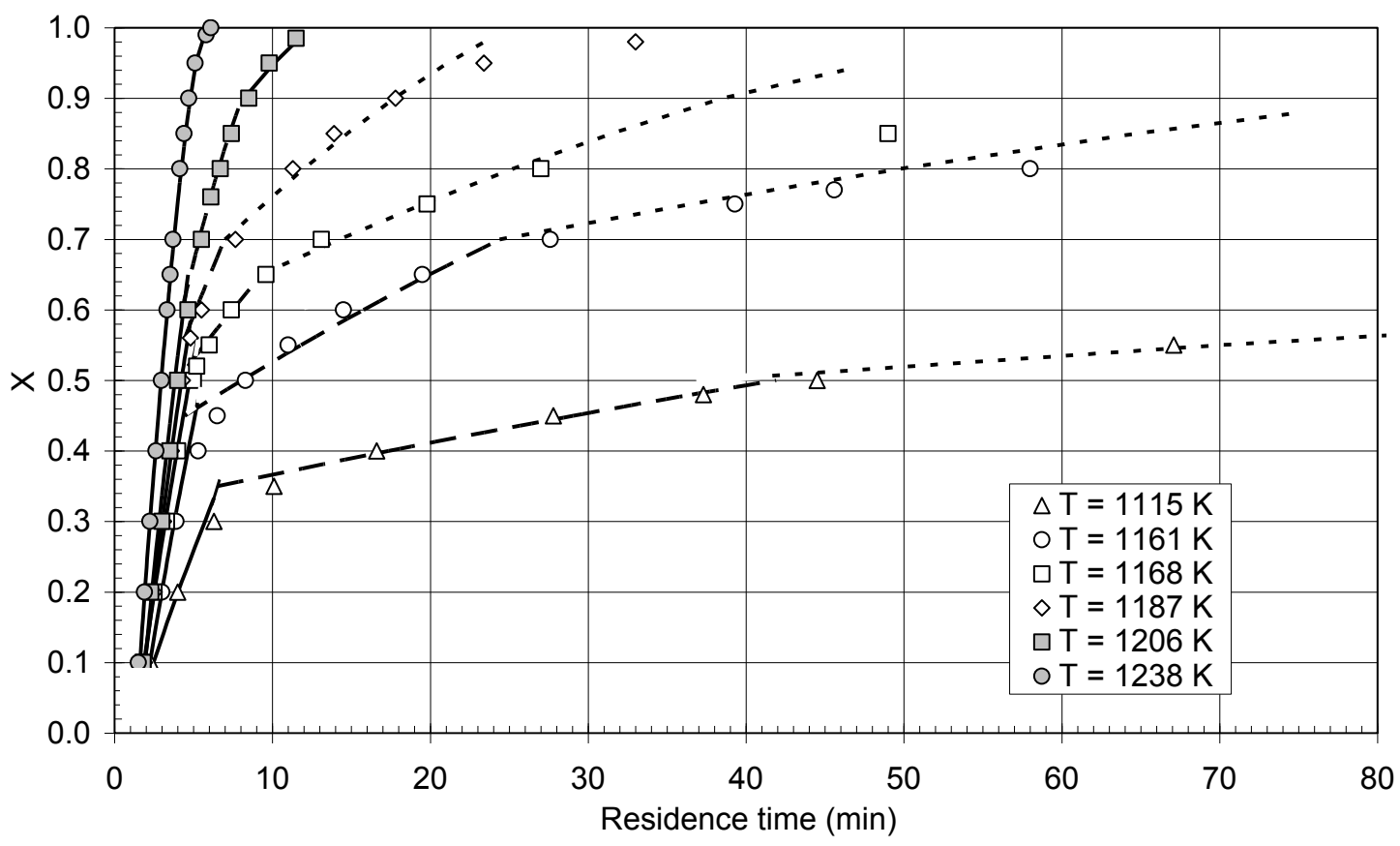

Figure 13 Fit of the experimental data obtained in a gas stream containing $100 \% \mathrm{CO}_{2}$ by volume at different temperatures to equations (3) (solid and dashed lines) and (4) (dotted lines). $\varepsilon_{0}=0.229 ; c_{B}^{0}=2.925 \mathrm{kmol} / \mathrm{m}^{3} ; L=0.007 \mathrm{~m}$ 


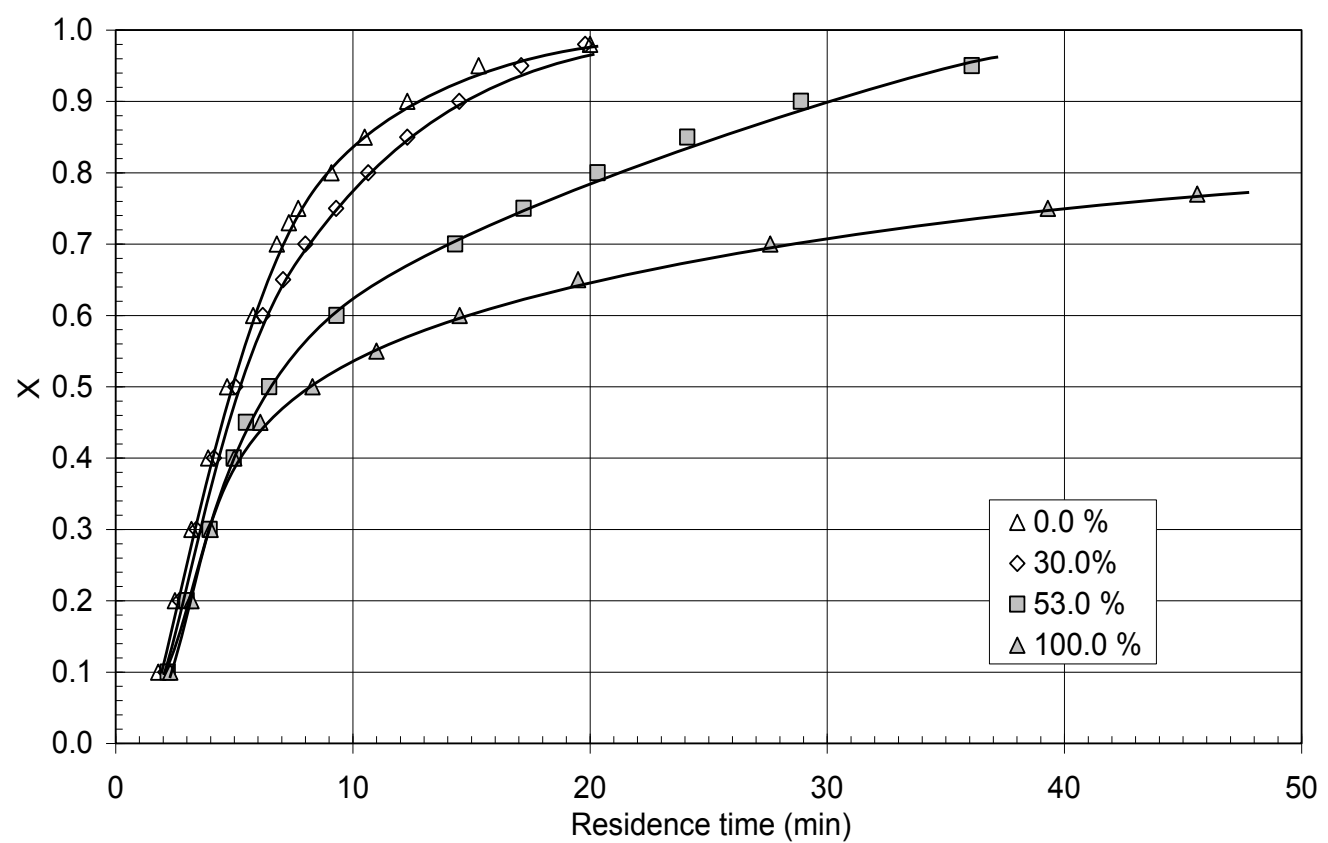

Figure 14 Comparison of the experimental data obtained in a gas stream containing different $\mathrm{CO}_{2}$ concentrations $T=1161 \mathrm{~K} ; \varepsilon_{0}=0.229 ; C_{B}^{0}=2.925 \mathrm{kmol} / \mathrm{m}^{3} ; L=$ $0.007 \mathrm{~m}$.

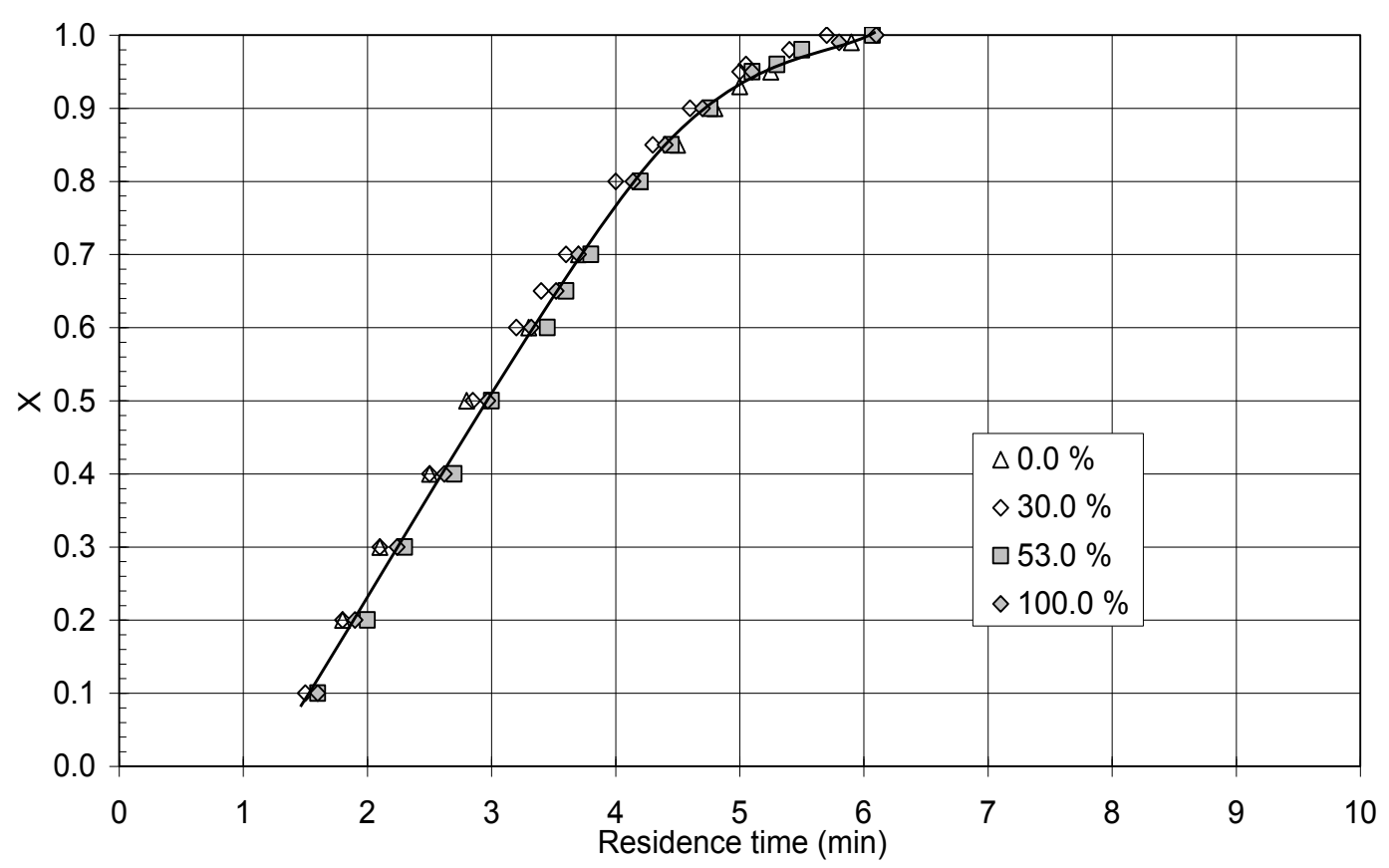

Figure 15 Comparison of the experimental data obtained in a gas stream containing different $\mathrm{CO}_{2}$ concentrations $T=1238 \mathrm{~K} ; \varepsilon_{0}=0.227 ; c_{B}^{0}=2.925 \mathrm{kmol} / \mathrm{m}^{3} ; L=0.007 \mathrm{~m}$. 


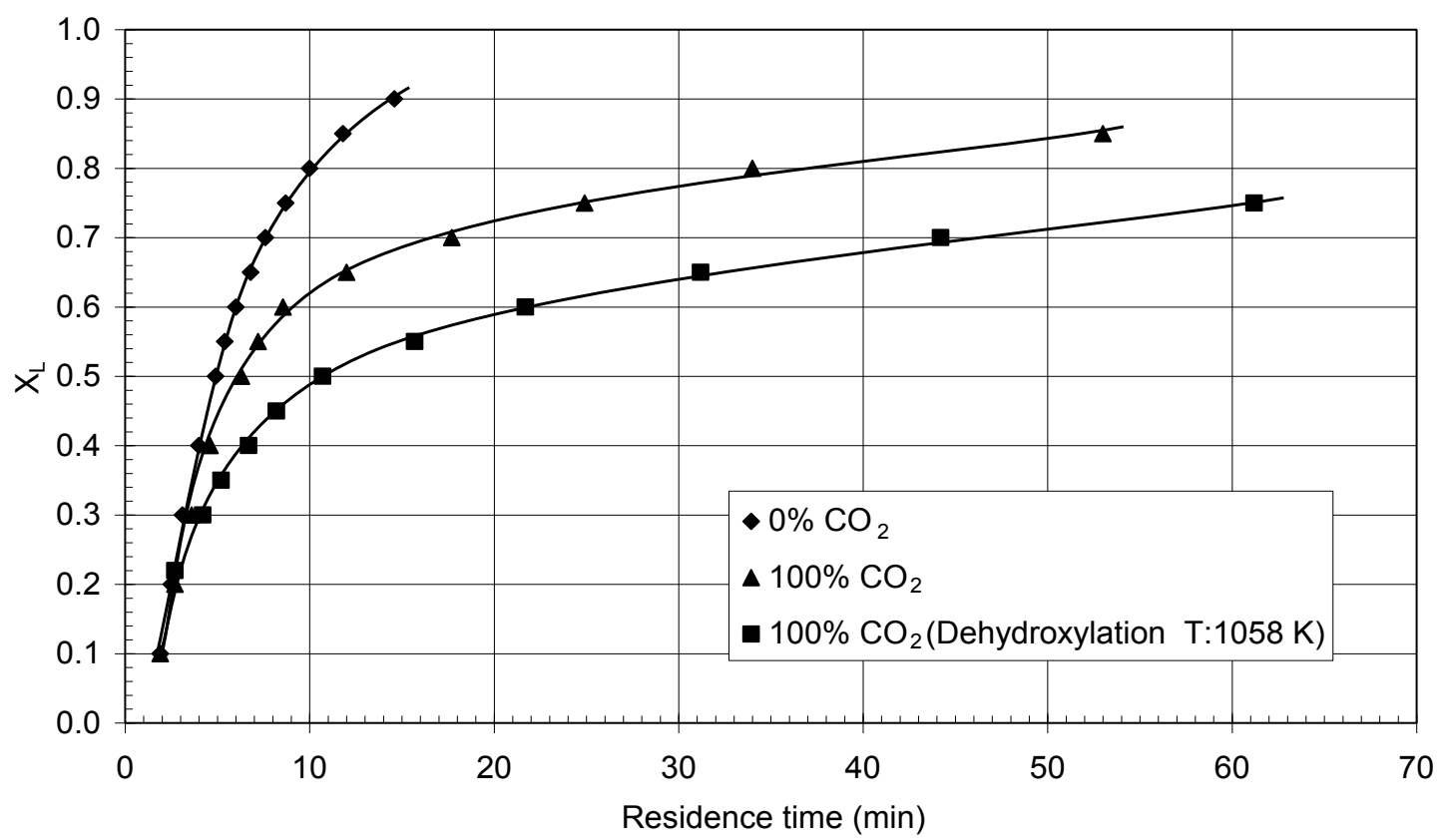

Figure 16 Comparison of the results obtained in experiments conducted under different operating conditions $T=1168 \mathrm{~K} ; \varepsilon_{0}=0.229 ; c_{B}^{0}=2.925 \mathrm{kmol} / \mathrm{m}^{3} ; L=0.007 \mathrm{~m}$.

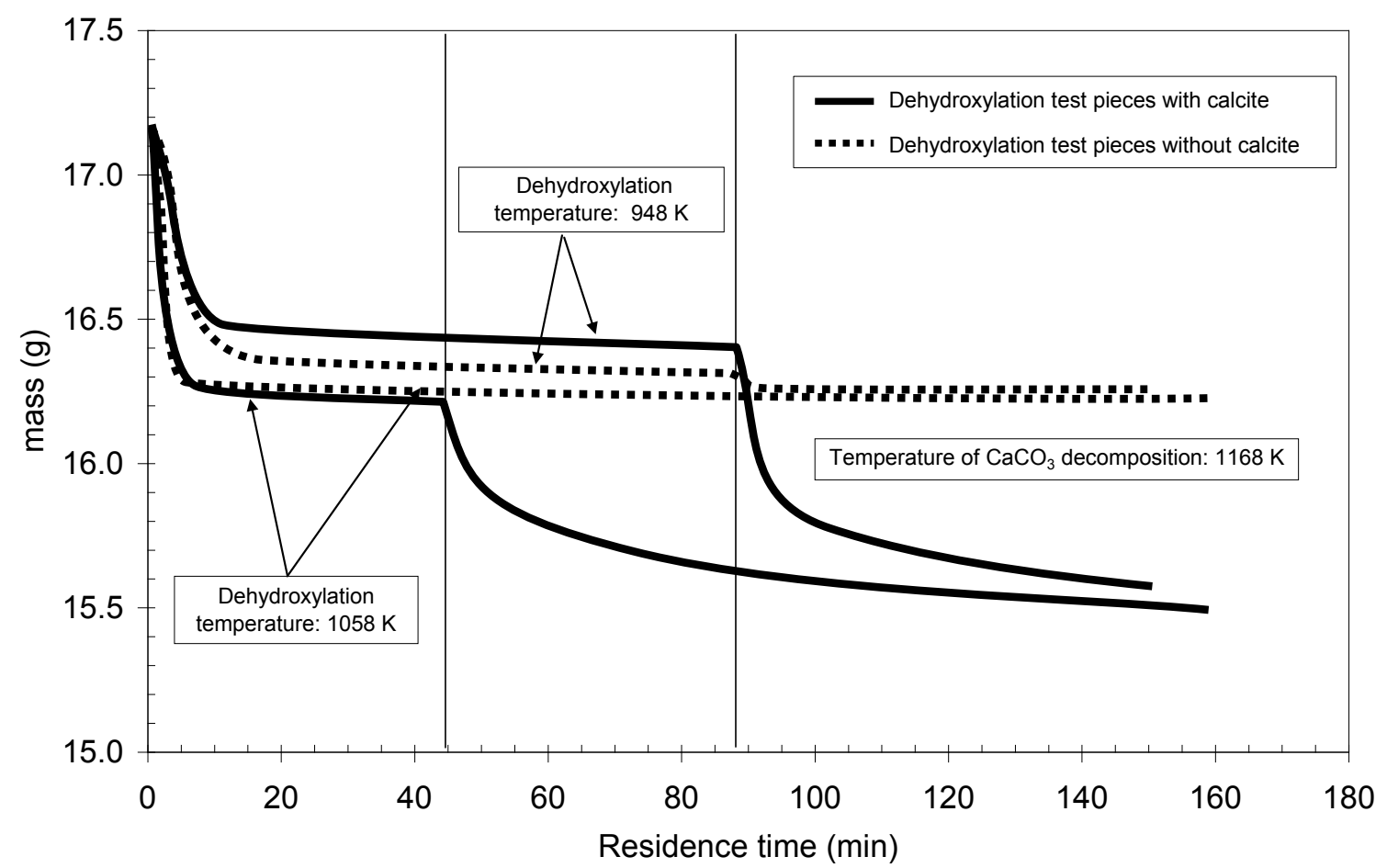

Figure 17 Dehydroxylation tests 